\title{
The Chemistry of Atmosphere-Forest Exchange (CAFE) Model - Part 2: Application to BEARPEX-2007 observations
}

\author{
G. M. Wolfe ${ }^{1,2}$, J. A. Thornton ${ }^{2}$, N. C. Bouvier-Brown ${ }^{3, *}$, A. H. Goldstein ${ }^{3}$, J.-H. Park ${ }^{3}$, M. McKay ${ }^{3, *}$, \\ D. M. Matross ${ }^{3,{ }^{* * *}}$, J. Mao ${ }^{4, * * *}$, W. H. Brune ${ }^{4}$, B. W. LaFranchi ${ }^{5, * * * *}$, E. C. Browne ${ }^{5}$, K.-E. Min ${ }^{5}$, P. J. Wooldridge ${ }^{5}$, \\ R. C. Cohen ${ }^{5}$, J. D. Crounse ${ }^{6}$, I. C. Faloona ${ }^{7}$, J. B. Gilman ${ }^{8,9}$, W. C. Kuster ${ }^{8}$, J. A. de Gouw ${ }^{8,9}$, A. Huisman ${ }^{10}$, and \\ F. N. Keutsch ${ }^{10}$ \\ ${ }^{1}$ Department of Chemistry, University of Washington, Seattle, WA, USA \\ ${ }^{2}$ Department of Atmospheric Sciences, University of Washington, Seattle, WA, USA \\ ${ }^{3}$ Department of Environmental Science, Policy, and Management, University of California, Berkeley, CA, USA \\ ${ }^{4}$ Department of Meteorology, Pennsylvania State University, University Park, PA, USA \\ ${ }^{5}$ Department of Chemistry, University of California, Berkeley, CA, USA \\ ${ }^{6}$ Division of Chemistry and Chemical Engineering, California Institute of Technology, Pasadena, CA, USA \\ ${ }^{7}$ Department of Land, Air and Water Resources, University of California, Davis, CA, USA \\ ${ }^{8}$ NOAA Earth System Research Laboratory, Boulder, CO, USA \\ ${ }^{9}$ Cooperative Institute for Research in Environmental Sciences, University of Colorado, Boulder, CO, USA \\ ${ }^{10}$ Department of Chemistry, University of Wisconsin, Madison, WI, USA \\ *now at: Chemistry and Biochemistry Department, Loyola Marymount University, Los Angeles, CA, USA \\ ** now at: California Air Resources Board, Sacramento, CA, USA \\ *** now at: KEMA, Inc., Oakland, CA, USA \\ *****now at: School of Engineering and Applied Sciences, Harvard University, Cambridge, MA, USA \\ ****** now at: Center for Accelerator Mass Spectrometry (CAMS), Lawrence Livermore National Lab, Livermore, CA, USA
}

Received: 24 August 2010 - Published in Atmos. Chem. Phys. Discuss.: 20 September 2010

Revised: 29 January 2011 - Accepted: 1 February 2011 - Published: 15 February 2011

\begin{abstract}
In a companion paper, we introduced the Chemistry of Atmosphere-Forest Exchange (CAFE) model, a vertically-resolved 1-D chemical transport model designed to probe the details of near-surface reactive gas exchange. Here, we apply CAFE to noontime observations from the 2007 Biosphere Effects on Aerosols and Photochemistry Experiment (BEARPEX-2007). In this work we evaluate the CAFE modeling approach, demonstrate the significance of in-canopy chemistry for forest-atmosphere exchange and identify key shortcomings in the current understanding of intra-canopy processes.

CAFE generally reproduces BEARPEX-2007 observations but requires an enhanced radical recycling mechanism to overcome a factor of 6 underestimate of hydroxyl $(\mathrm{OH})$ concentrations observed during a warm $\left(\sim 29^{\circ} \mathrm{C}\right)$ period. Modeled fluxes of acyl peroxy nitrates (APN) are quite sensitive to gradients in chemical production and loss, demonstrating that chemistry may perturb forest-atmosphere exchange
\end{abstract}

Correspondence to: J. A. Thornton (thornton@atmos.washington.edu) even when the chemical timescale is long relative to the canopy mixing timescale. The model underestimates peroxy acetyl nitrate (PAN) fluxes by $50 \%$ and the exchange velocity by nearly a factor of three under warmer conditions, suggesting that near-surface APN sinks are underestimated relative to the sources. Nitric acid typically dominates gross dry $\mathrm{N}$ deposition at this site, though other reactive nitrogen $\left(\mathrm{NO}_{\mathrm{y}}\right)$ species can comprise up to $28 \%$ of the $\mathrm{N}$ deposition budget under cooler conditions. Upward $\mathrm{NO}_{2}$ fluxes cause the net above-canopy $\mathrm{NO}_{\mathrm{y}}$ flux to be $\sim 30 \%$ lower than the gross depositional flux. CAFE under-predicts ozone fluxes and exchange velocities by $\sim 20 \%$. Large uncertainty in the parameterization of cuticular and ground deposition precludes conclusive attribution of non-stomatal fluxes to chemistry or surface uptake. Model-measurement comparisons of vertical concentration gradients for several emitted species suggests that the lower canopy airspace may be only weakly coupled with the upper canopy. Future efforts to model forestatmosphere exchange will require a more mechanistic understanding of non-stomatal deposition and a more thorough characterization of in-canopy mixing processes. 


\section{Introduction}

Forest-atmosphere exchange of hydrocarbons, ozone, oxidized nitrogen and other reactive species impacts both atmospheric composition and ecosystem productivity, with broad implications for air quality and climate (Goldstein et al., 2009; Isaksen et al., 2009; Fowler et al., 2009; Erisman et al., 1998). Quantifying deposition and emission to/from the forest, however, continues to present a significant experimental and theoretical challenge. Recent work has indicated that the air within and just above the canopy is highly oxidizing during the daytime (Farmer and Cohen, 2008; Holzinger et al., 2005; Lelieveld et al., 2008). This oxidative photochemistry affects the net biosphere-atmosphere exchange of many species. For example, the "escape efficiency" of highly reactive terpenoids is likely much less than unity (Ciccioli et al., 1999; Stroud et al., 2005; Bouvier-Brown et al., 2009a; Forkel et al., 2006), with consequences for scaling up leaflevel emissions for use in regional and global models. As a substantial in-canopy sink for oxidants like ozone $\left(\mathrm{O}_{3}\right)$, this chemistry could also contribute to downward $\mathrm{O}_{3}$ fluxes (Goldstein et al., 2004; Kurpius and Goldstein, 2003; Fares et al., 2010a).

Chemistry can also influence surface fluxes of reactive nitrogen compounds, including $\mathrm{NO}_{\mathrm{x}}\left(\equiv \mathrm{NO}+\mathrm{NO}_{2}\right)$, acyl peroxy nitrates (APNs), alkyl nitrates (ANs) and nitric acid $\left(\mathrm{HNO}_{3}\right)$. Several measurement and modeling studies have demonstrated the influence of in-canopy gradients in radiation, $\mathrm{O}_{3}$ and turbulent transport on fluxes of $\mathrm{NO}_{\mathrm{x}}(\mathrm{Gao}$ et al., 1991; Dorsey et al., 2004; Duyzer et al., 2004) and the need to resolve canopy-scale processes in regional and global models (Ganzeveld et al., 2002a, b). One set of observations showing upward $\mathrm{HNO}_{3}$ and APN fluxes over a young Ponderosa pine plantation suggests that, under certain conditions, intra-canopy chemistry may even alter the sign of fluxes traditionally assumed to be controlled by deposition (Farmer and Cohen, 2008). More recently, Wolfe et al. (2009) observed downward APN fluxes at this same forest, but determined that the magnitude of the flux was sensitive to multiple in-canopy processes, including deposition, thermal decomposition and photochemical production.

Numerical modeling is an ideal tool for examining the interplay of physical and chemical processes contributing to net reactive gas exchange. Here, we apply the Chemistry of Atmosphere-Forest Exchange (CAFE) model to the comprehensive dataset from the Biosphere Effects on Aerosols and Photochemistry Experiment (BEARPEX) 2007 field campaign to investigate forest-atmosphere exchange at a young Ponderosa pine plantation. After a brief description of BEARPEX-2007 and a review of the key features of CAFE, we proceed with a detailed evaluation of observations from BEARPEX-2007. Our analysis focuses on the mechanisms controlling concentrations and fluxes of VOCs, hydrogen oxides, ozone, and reactive nitrogen.

\section{Methods}

\subsection{Campaign and site description}

BEARPEX-2007 was a multi-institutional collaborative research effort aimed at understanding the impact of forestatmosphere interactions on atmospheric composition. During the intensive measurement period of 15 August to 10 October 2007, a wide suite of chemical and meteorological observations were obtained within and immediately above a 17-yr-old Ponderosa pine plantation managed by Sierra Pacific Industries. The site is adjacent to the University of California's Blodgett Forest Research Station (BFRS), located in the western foothills of the Sierra Nevada Mountains, CA $\left(38^{\circ} 58^{\prime} 42.9^{\prime \prime} \mathrm{N}, 120^{\circ} 57^{\prime} 57.9^{\prime \prime} \mathrm{W}\right.$, elevation $\left.1315 \mathrm{~m}\right)$, and has been described in detail elsewhere (Goldstein et al., 2000). The BFRS overstory is primarily Ponderosa pine, with a few interspersed White fir, Douglas fir, Incense cedar, Black oak and Sugar pine, while the understory consists of Manzanita and Ceanothus shrubs.

For the current study, we simulate mean noontime (11:3012:30 PST) observations from two sub-periods, designated "hot" (28 August-3 September, or day of year 240-246) and "cool" (13-18 September, or day of year 256-261). These windows were chosen because day-to-day meteorology (particularly temperature) is fairly uniform throughout each period, and because they contain the most overlap among chemical observations. Figure 1 illustrates near-surface temperature profiles for each period; the average temperature difference between the two periods is $\sim 10^{\circ} \mathrm{C}$. The hot and cool periods are representative of the general meteorological trend observed during BEARPEX-2007, characterized by a hot and dry August followed by a sharp transition to cooler, more humid conditions in September (Bouvier-Brown et al., 2009a; Wolfe et al., 2009); however, neither period is representative of the extreme conditions sampled during the campaign. Both periods are largely cloud free and remain under drought conditions, as the selected cool period precedes the first rain. Chemical observations from these periods are discussed in Sect. 3 and are summarized in Table S1 of the Supplement.

\subsection{Model description}

CAFE is a 1-D chemical transport model that resolves deposition, emission, chemistry and vertical diffusion throughout the canopy and mixed layer. The CAFE model and the details of its setup for BFRS are described in a companion paper (Wolfe and Thornton, 2011), and we will only briefly review the key aspects and modifications here. Table 1 lists important model parameters. The model domain consists of 86 layers in the vertical ranging from $0.01 \mathrm{~m}$ to $800 \mathrm{~m}$, with noneven layer spacing that results in a fine-resolution grid of 36 layers within the forest canopy and 50 within the atmospheric boundary layer $(\mathrm{ABL})$. High resolution within the canopy provides the greatest detail where vertical gradients in all 
Table 1. Model parameters.

\begin{tabular}{llll}
\hline Parameter & Symbol & Value & Units \\
\hline Overstory height & $h$ & 10 & $\mathrm{~m}$ \\
Understory height & $h_{\mathrm{us}}$ & 2 & $\mathrm{~m}$ \\
Atmospheric boundary layer height & $h_{\mathrm{ABL}}$ & 800 & $\mathrm{~m}$ \\
Overstory leaf area index & $\mathrm{LAI}_{\mathrm{Os}}$ & 3.2 & $\mathrm{~m}^{2} \mathrm{~m}^{-2}$ \\
Understory leaf area index & $\mathrm{LAI}_{\mathrm{us}}$ & 1.9 & $\mathrm{~m}^{2} \mathrm{~m}^{-2}$ \\
Overstory dry leaf mass & $d_{\mathrm{Os}}$ & 219 & $\mathrm{~g} \mathrm{~m}^{-2}$ \\
Understory dry leaf mass & $d_{\mathrm{us}}$ & 377 & $\mathrm{~g} \mathrm{~m}^{-2}$ \\
Radiation extinction coefficient & $k_{\mathrm{rad}}$ & 0.4 & - \\
Diffusion timescale ratio & $\tau / T_{\mathrm{L}}$ & 4 & - \\
NO basal emission rate & $E_{\mathrm{NO}}^{\mathrm{b}}$ & 3 & $\mathrm{ngN} \mathrm{m}$ \\
Integration interval & $\Delta t$ & 2 & $\mathrm{~s}$ \\
Chemistry time step & - & 0.05 & $\mathrm{~s}$ \\
Diffusion time step & - & 0.05 & $\mathrm{~s}$ \\
Total integration time & - & 7200 & $\mathrm{~s}$ \\
\hline
\end{tabular}

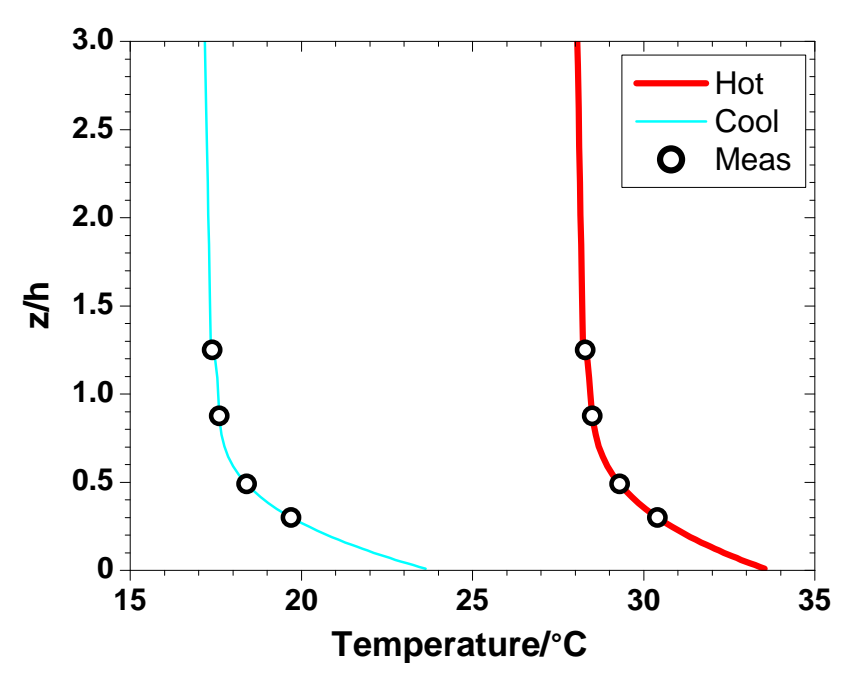

Fig. 1. Measured (open circles) and model-parameterized (solid lines) near-surface temperature profiles for the hot and cool periods.

processes are largest and minimizes numerical artifacts from operator-splitting of chemistry and diffusion. Within each layer, the 1-D time-dependent continuity equation is solved to determine the rate of change for all chemical species:

$\frac{\partial C(z)}{\partial t}=P(z)+L(z)+E(z)+D(z)+A(z)-\frac{\partial F(z)}{\partial z}$

Terms on the right respectively represent rates of chemical production, chemical loss, emission, deposition, advection (horizontal mixing) and vertical turbulent flux divergence. In its current form, CAFE is designed to calculate steady-state concentration and flux profiles, i.e. it is not meant to perform as a prognostic model.
The resolved canopy includes an overstory with a height of $10 \mathrm{~m}$, a one-sided leaf area index (LAI) of $3.2 \mathrm{~m}^{2} \mathrm{~m}^{-2}$ and a leaf area dry mass $(d)$ of $219 \mathrm{~g} \mathrm{~m}^{-2}$, as well as an understory with a height of $2 \mathrm{~m}$, an LAI of $1.9 \mathrm{~m}^{2} \mathrm{~m}^{-2}$ and a $d$ of $377 \mathrm{~g} \mathrm{~m}^{-2}$. The leaf area density function (LADF), which describes how leaf area is distributed vertically, mimics observed vegetation structures (L. Misson, personal communication, 2008). Meteorological constraints, which are held constant throughout a model run, are taken as the mean noontime observations from the hot and cool periods (Table 2) with further parameterizations as outlined in the companion paper. Of particular importance for the current study is the imposed canopy microclimate, as this plays a large role in both chemistry and vertical mixing. Temperature is interpolated via a spline fit between four measurements ranging from 12.5 to $3 \mathrm{~m}$ and extrapolated to the ground (Fig. 1). This treatment is consistent with observations at $1.5 \mathrm{~m}$ recorded during BEARPEX-2009 (R. Weber, personal communication, 2010). Friction velocity $\left(u^{*}\right)$ and radiation were only measured above the canopy, thus their in-canopy profiles are estimated using standard parameterizations that assume an exponential decay as a function of cumulative leaf area. For BFRS, this results in a factor of 10 decrease in both $u^{*}$ and radiation between the top of the canopy and the ground. Schade et al. (2000) note that the top-down radiation attenuation algorithm is not optimized for coniferous forests as it does not explicitly account for "clumping" of needles. The flexibility of our simple exponential parameterization should minimize this problem via a judicious choice for the radiation extinction coefficient, $k_{\mathrm{rad}}$, as detailed in the companion paper.

Turbulent diffusion is represented using a first-order fluxgradient approach, also known as K-theory:

$$
\frac{\partial F(z)}{\partial z}=-\frac{\partial}{\partial z}\left(K(z) \frac{\partial C(z)}{\partial z}\right)
$$


Table 2. Meteorological observations.

\begin{tabular}{lllll}
\hline Parameter & Symbol & Hot & Cool & Units \\
\hline Air Temperature $^{\mathrm{a}}$ & $T$ & $30.5-28.4$ & $19.8-17.5$ & ${ }^{\circ} \mathrm{C}$ \\
Surface pressure $^{\mathrm{b}}$ & $P$ & 870 & 868 & $\mathrm{mbar}^{-2}$ \\
Actinic flux $^{\mathrm{b}}$ & $\mathrm{RAD}$ & 674 & 618 & $\mathrm{~W} \mathrm{~m}^{-2}$ \\
Photosynthetically Active Radiation $^{\mathrm{b}}$ & $\mathrm{PAR}$ & 1758 & 1595 & $\mathrm{umol} \mathrm{m}^{-2} \mathrm{~s}^{-1}$ \\
Water vapor concentration $^{\mathrm{b}}$ & $\mathrm{H}{ }_{2} \mathrm{O}$ & 10.8 & 10.3 & $\mathrm{mmol} \mathrm{mol}^{-1}$ \\
Vapor pressure deficit $^{\mathrm{b}}$ & $\mathrm{VPD}$ & 2.91 & 1.10 & $\mathrm{kPa}^{\mathrm{a}}$ \\
Friction velocity $^{\mathrm{b}}$ & $u^{*}$ & 0.63 & 0.68 & $\mathrm{~m} \mathrm{~s}^{-1}$ \\
Solar Zenith Angle $^{\mathrm{c}}$ & $\mathrm{SZA}$ & 30.4 & 36.3 & degrees \\
\hline
\end{tabular}

a Range of measurements from $3.0-12.5 \mathrm{~m}$.

b Measured at $12.5 \mathrm{~m}$.

${ }^{\mathrm{c}}$ From TUV model.

${ }^{\mathrm{d}}$ Divide by 2.92 to convert to $\mathrm{W} \mathrm{m}^{-2}$.

Above $12.5 \mathrm{~m}$, the eddy diffusion coefficient, $K(z)$, is based on values used by Gao et al. (1993), scaled to an ABL height of $800 \mathrm{~m}$. Below $12.5 \mathrm{~m}, K(z)$ is a function of friction velocity and canopy height and includes a correction factor to account for "near-field" effects of canopy elements on eddy diffusion (Makar et al., 1999; Raupach, 1989), though the latter is close to unity for the current study. As detailed further in Wolfe and Thornton (2011), diffusion coefficients are constrained by several metrics, including comparison with above-canopy flux-gradient relationships of nonreactive scalars and with previous estimates of the canopy mixing timescale. The resultant canopy residence time is $\sim 2$ min for our conditions.

Emissions of biogenic VOC (BVOC), including 2-methyl3-buten-2-ol (MBO), isoprene $\left(\mathrm{C}_{5} \mathrm{H}_{8}\right)$, methyl chavicol (MCHAV, also known as estragole), and a suite of speciated monoterpenes (MT) and sesquiterpenes (SQT), are modeled in each canopy layer as a function of leaf density, light, temperature and vegetation density. For each emitted compound and in each layer, the emission rate is calculated in units of molecules $\mathrm{cm}^{-3} \mathrm{~s}^{-1}$ as

$E(z)=E_{\mathrm{b}} C_{\mathrm{L}}(z) C_{\mathrm{T}}(z)\left(d \frac{\operatorname{LADF}(z)}{\mathrm{LAI}}\right)$

$E_{\mathrm{b}}$ is the basal emission rate in molecules per gram of leaf per second, $C_{\mathrm{L}}(z)$ and $C_{\mathrm{T}}(z)$ are dimensionless correction factors for light and temperature (Guenther et al., 1995), and the rightmost terms collectively represent the vertically-distributed leaf dry mass in grams of leaf per cubic centimeter. Basal emission rates are prescribed separately for the overstory and understory within the range of values reported for this forest (Bouvier-Brown et al., 2009b, c; Harley et al., 1998; Schade et al., 2000) and are adjusted to optimize model-measurement agreement during the hot period. Temperature and light corrections are taken from the literature (Bouvier-Brown et al., 2009c; Guenther et al., 1995; Harley et al., 1998) and are calculated as a function of the imposed canopy microclimate in each layer. Speciated MT emissions include $\alpha$-pinene, $\beta$-pinene, limonene, 3 -carene, myrcene, camphene, terpinolene, $\alpha$-terpinene and $\gamma$-terpinene. SQT include $\alpha$-bergamotene (ABERG), $\beta$ caryophyllene (BCARY), $\alpha$-farnesene (AFARN) and unspeciated SQT (USQT). USQT are a proxy for the non-speciated SQT observations reported by Bouvier-Brown et al. (2009a, c). Soil NO emissions are a function of temperature assuming dry soil (Yienger and Levy, 1995; Williams et al., 1992) with a basal $\mathrm{NO}$ emission factor of $3 \mathrm{ngN} \mathrm{m}^{-2} \mathrm{~s}^{-1}$. This gives temperature-corrected NO emission fluxes of 3.0 and $2.4 \mathrm{ngN} \mathrm{m}^{-2} \mathrm{~s}^{-1}$ for the hot and cool periods, respectively. Direct observations of soil NO fluxes are not available for BEARPEX-2007; however, modeled values are consistent with preliminary results from BEARPEX-2009 measurements (E. Browne, personal communication, 2010).

Deposition is calculated for 35 species using a standard resistance parameterization (Wesely, 1989; Zhang et al., 2003; Wesely and Hicks, 2000) and includes transfer across the laminar sublayer, stomatal and cuticular uptake and ground deposition. The stomatal resistance calculation includes environmental corrections for light extinction, temperature and vapor pressure deficit (Zhang et al., 2003) and is optimized to agree with observationally-constrained, "top-down" calculations of stomatal resistance during BEARPEX-2007. Cuticular resistances are based on standard values used in other models; however, as these are not well-constrained by observations, we will note in the discussion when uncertainties in non-stomatal deposition might influence interpretation of modeled fluxes. Deposition resistances $\left(R_{\mathrm{dep}}(z)\right)$ for each species are calculated separately for the overstory and understory in each layer and scaled by LADF to give a first-order loss rate constant within each vertical layer:

$k_{\mathrm{dep}}(z)=\frac{\operatorname{LADF}(z)_{\mathrm{OS}}}{R_{\mathrm{dep}}(z)_{\mathrm{OS}}}+\frac{\operatorname{LADF}(z)_{\mathrm{US}}}{R_{\mathrm{dep}}(z)_{\mathrm{US}}}$ 
Multiplication of $k_{\mathrm{dep}}(z)$ by a concentration yields the firstorder depositional loss rates.

Chemistry in CAFE is based on a subset of the Master Chemical Mechanism (MCM) version 3.1 (http://mcm.leeds. ac.uk/MCM/) that includes all reactions stemming from oxidation of $\mathrm{MBO}$, isoprene, $\alpha$-pinene, $\beta$-pinene, propanal $\left(\mathrm{C}_{2} \mathrm{H}_{5} \mathrm{CHO}\right)$ and methane. MCM names and structures for key species mentioned in this study are listed in Appendix A. Our mechanism also includes a number of modifications and additions to the base MCM, most of which are described in the companion paper. Notably, CAFE incorporates a suite of 36 additional reactions for the initial oxidation of monoterpenes (excluding $\alpha$-pinene and $\beta$-pinene), sesquiterpenes and MCHAV by $\mathrm{OH}, \mathrm{O}_{3}$ and $\mathrm{NO}_{3}$. Products of these reactions include small oxidized VOC with yields as reported by laboratory oxidation studies (Atkinson and Arey, 2003; Lee et al., 2006a, b), hydroxyl (OH) radicals from ozonolysis reactions, also with literature-reported yields (Atkinson and Arey, 2003; Lee et al., 2006a), and the generic peroxy radicals $\mathrm{MTO}_{2}$ and $\mathrm{SQTO}_{2}$. The latter react with $\mathrm{NO}, \mathrm{HO}_{2}$ and $\mathrm{RO}_{2}$ to form the species MTOX and SQTOX, which represent first-generation oxidation products of MT and SQT. Since these products are likely semi-volatile and their detailed chemistry is presently unknown, MTOX and SQTOX are given a deposition velocity equal to that of nitric acid (near the aerodynamic limit) and do not undergo further reactions. CAFE also incorporates isoprene dihydroxyepoxide chemistry (Paulot et al., 2009c) and assumes that the epoxide (IEPOX) deposits at the aerodynamic limit.

For the current investigation, we implement one significant modification to the default mechanism described in Wolfe and Thornton (2011). When VOC emissions are high (i.e. during the hot period), an additional "enhanced $\mathrm{OH}$ recycling" mechanism is required to bring modeled $\mathrm{OH}$ values into agreement with measurements. We employ a mechanism of the type

$\mathrm{RO}_{2}+\mathrm{HO}_{2} \stackrel{k_{\mathrm{rec}}}{\longrightarrow} \alpha \mathrm{OH}+$ products

where $\alpha$ is a stoichiometric constant. These reactions, listed in Table 3, are implemented only for first-generation MBO and isoprene-derived peroxy radicals $\left(\mathrm{RO}_{2}=\mathrm{MBOAO}_{2}\right.$, $\mathrm{MBOBO}_{2}$, ISOPAO2, ISOPBO ${ }_{2}, \mathrm{ISOPCO}_{2}$ and $\mathrm{ISOPDO}_{2}$ ). The reaction "products" are those of the decomposition of the corresponding RO radicals, which are explicitly tracked. Values for $\alpha$ and $k_{\text {rec }}$ are tuned to optimize model-measurement agreement for $\mathrm{OH}$ and $\mathrm{HO}_{2}$; for the current study, we choose $\alpha=2.6$ and $\mathrm{k}_{\text {rec }}=4.5 \times 10^{-11} \mathrm{~cm}^{3} \mathrm{molec}^{-1} \mathrm{~s}^{-1}$. We discuss and evaluate the consequences of this mechanistic change further in Sect. 3.2.
Advection is treated as a simple mixing process in each model layer with a mixing rate constant $\left(k_{\text {mix }}\right)$ of $0.3 \mathrm{~h}^{-1}$ (Dillon et al., 2002; Perez et al., 2009):

$$
\left(\frac{d C}{d t}\right)_{\text {mix }}=-k_{\text {mix }}\left(C-C_{\mathrm{a}}\right)
$$

Advection concentrations $\left(C_{\mathrm{a}}\right)$ are set constant throughout the model domain but are different for the hot and cool periods (Table 4). This scheme maintains reasonable concentrations for species that would otherwise build up to unreasonable values or decay below measured values during integration. Advection thus allows us to better constrain CAFE to BEARPEX-2007 observations. We will note when this term influences the interpretation of results, though it generally does not influence modeled exchange velocities as the timescale for advection is relatively long (several hours).

For each period, meteorological observations (Table 2) are used to initialize diffusion parameters, emission rates, deposition velocities and chemical rate constants, which are held constant throughout a model run. Chemical concentrations are initialized with the same values used in the advection scheme (Table 4) and are thus constant throughout the vertical; these values are chosen to optimize model agreement with observations. Integration is accomplished via operator splitting using a Crank-Nicolson scheme to solve the diffusion operator and a forward Euler scheme for the chemical operator (Jacobson, 2005). Soil NO emission and ground deposition are incorporated into the diffusion operator, while canopy emissions, deposition and advection are represented in the chemistry operator. The model is run for two hours, which is sufficient time for relaxation of exchange velocity profiles. Fluxes and exchange velocities are calculated from concentration profiles at the end of a model run via

$$
\begin{aligned}
& F(z)=-K(z) \frac{\Delta C(z)}{\Delta z} \\
& V_{\mathrm{ex}}(z)=F(z) / C(z)
\end{aligned}
$$

\section{Results and discussion}

In what follows, we compare CAFE model output with observations from the BEARPEX-2007 field campaign. Table S1 in the Supplement lists averaged chemical observations for each period. All quoted measurement values represent the means and standard deviations of 30-min averaged data. The hot period is typified by relatively high concentrations of BVOC, $\mathrm{HO}_{x}, \mathrm{O}_{3}$ and oxygenated hydrocarbons and lower levels of $\mathrm{NO}_{2}$ and acyl peroxy nitrates $(\mathrm{APN}=\mathrm{PAN}+\mathrm{PPN}+\mathrm{MPAN}+\ldots)$; cold period data demonstrate the opposite trends. Differences in local atmospheric composition between the hot and cool periods are largely driven by temperature (as opposed to wind direction, for example), which controls emission rates and subsequent 
Table 3. Enhanced OH-recycling reactions. All reactions have a rate constant of $4.5 \times 10^{-11} \mathrm{~cm}^{3} \mathrm{molec}^{-1} \mathrm{~s}^{-1}$. $\alpha$ is set to 2.6 .

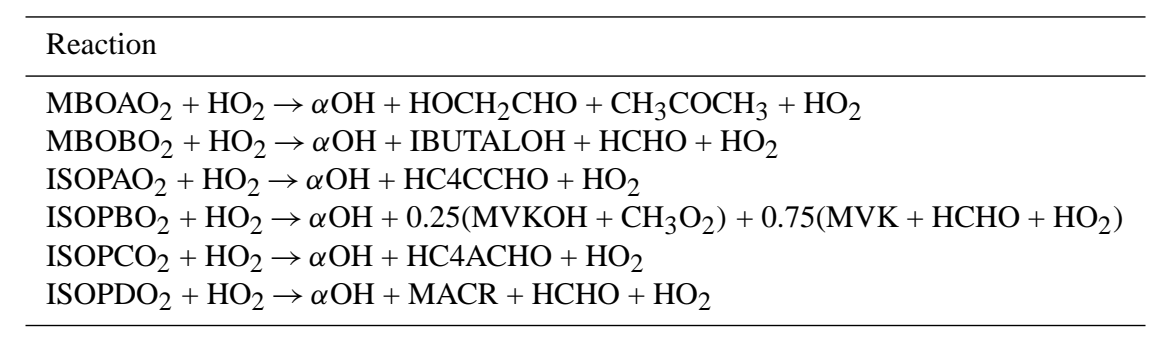

Table 4. Initial/advection concentrations in ppbv. Species not listed have initial/advection concentrations set to 0 .

\begin{tabular}{|c|c|c|c|c|c|}
\hline \multirow[t]{2}{*}{ Species } & \multicolumn{2}{|c|}{ Mixing Ratio/ppbv } & \multirow[t]{2}{*}{ Species } & \multicolumn{2}{|c|}{ Mixing Ratio/ppbv } \\
\hline & Hot & Cool & & Hot & Cool \\
\hline $\mathrm{OH}$ & $3 \times 10^{-4}$ & $1 \times 10^{-4}$ & Aldehydes & & \\
\hline $\mathrm{HO}_{2}$ & 0.03 & 0.02 & $\mathrm{HCHO}$ & 3 & 1 \\
\hline $\mathrm{CO}$ & 97 & 116 & $\mathrm{CH}_{3} \mathrm{CHO}$ & 0.5 & 0.5 \\
\hline $\mathrm{O}_{3}$ & 53 & 45 & $\mathrm{C}_{2} \mathrm{H}_{5} \mathrm{CHO}$ & 0.13 & 0.13 \\
\hline \multirow[t]{2}{*}{$\mathrm{H}_{2} \mathrm{O}_{2}$} & 0.85 & 0.8 & MACR & 0.1 & 0.3 \\
\hline & & & GLYOX & 0.02 & 0.045 \\
\hline \multicolumn{6}{|l|}{$N O_{\mathrm{y}}$} \\
\hline $\mathrm{NO}$ & 0.06 & 0.1 & Hydrocarbons & & \\
\hline $\mathrm{NO}_{2}$ & 0.3 & 0.8 & $\mathrm{CH}_{4}$ & 1600 & 1600 \\
\hline $\mathrm{HNO}_{3}$ & 0.82 & 0.23 & isoprene & 4 & 0.2 \\
\hline PAN & 0 & 0.26 & $\mathrm{C}_{3} \mathrm{H}_{6}$ & 0.1 & 0.1 \\
\hline PPN & 0 & 0.02 & & & \\
\hline MPAN & 0 & 0.03 & Ketones & & \\
\hline $\mathrm{MBOANO}_{3}$ & 0.05 & 0.04 & $\mathrm{CH}_{3} \mathrm{COCH}_{3}$ & 1.5 & 1.7 \\
\hline $\mathrm{MBOBNO}_{3}$ & 0.04 & 0.03 & MVK & 1.6 & 0.2 \\
\hline $\mathrm{ISOPANO}_{3}$ & 0.03 & 0.02 & ACETOL & 0 & 0.02 \\
\hline $\mathrm{ISOPBNO}_{3}$ & 0.04 & 0.03 & & & \\
\hline $\mathrm{ISOPCNO}_{3}$ & 0.03 & 0.02 & Organic Acids & & \\
\hline $\mathrm{ISOPDNO}_{3}$ & 0.03 & 0.02 & $\mathrm{CH}_{3} \mathrm{CO}_{2} \mathrm{H}$ & 6 & 2.8 \\
\hline $\mathrm{MACRNO}_{3}$ & 0.005 & 0.004 & $\mathrm{HCOOH}$ & 5.5 & 3.3 \\
\hline $\mathrm{HMVKANO}_{3}$ & 0.01 & 0.005 & $\mathrm{CH}_{3} \mathrm{CO}_{3} \mathrm{H}$ & 0.24 & 0.16 \\
\hline Alcohols & & & Other & & \\
\hline MBO & 1 & 0.15 & MCHAV & 0 & 0 \\
\hline $\mathrm{CH}_{3} \mathrm{OH}$ & 5.6 & 4.6 & MT (all) & 0 & 0 \\
\hline $\mathrm{C}_{2} \mathrm{H}_{5} \mathrm{OH}$ & 1.8 & 1.6 & SQT (all) & 0 & 0 \\
\hline IPROPOL & 0.09 & 0.09 & IEPOX & 0 & 0 \\
\hline
\end{tabular}

photochemistry. Model results are examined with a particular focus on $\mathrm{BVOC}, \mathrm{RO}_{\mathrm{x}}\left(=\mathrm{OH}+\mathrm{HO}_{2}+\mathrm{RO}_{2}\right)$, hydrogen peroxides, $\mathrm{O}_{3}$ and reactive nitrogen $\left(\mathrm{NO}_{\mathrm{y}}\right)$. We evaluate modifications implemented in the CAFE model (e.g. OH recycling) and provide an assessment of the relative contributions of deposition, emission and chemistry to above-canopy chemical fluxes for key species. Unless otherwise specified, model results discussed below are extracted from two "base" model runs, one each for the hot and cool periods. The base run for the hot period is carried out with the $\mathrm{OH}$-recycling mechanism, while the base cold period run does not include
OH-recycling. The reasons for this choice are detailed in Sect. 3.2.

Reproducing observed concentrations is important for examining chemical contributions to fluxes, but we caution that the model is not strictly tailored towards reproducing all aspects of the chemistry (e.g. diurnal cycles) or, more importantly, horizontal transport. Modeled mixing ratios are, in a sense, constrained to observations via the advection term and the initial/advection concentrations. We run CAFE in this fashion because our primary goal is to understand the observed fluxes, though we also point out other interesting 
features in the model-measurement comparison when they arise. Modeled concentration and fluxes should not be taken as representative of daily or seasonal "average" conditions, but rather as mid-day "snapshots" from the two periods. An extended comparison table of modeled and measured concentrations can be found in Table S2 of the Supplement.

\subsection{VOC}

Within and immediately above the forest, concentrations of primary BVOC (MBO, isoprene, MCHAV, MT and SQT) are controlled by relative rates of emission and oxidation. Calculation of "bulk canopy" emission rates provides a means for validation of vertically-resolved emissions. Taking MBO as an example: integration of the hot-period MBO emission rate over the canopy height gives a bulk emission rate of $5.2 \times 10^{11} \mathrm{molec} \mathrm{cm}^{-2} \mathrm{~s}^{-1}\left(1.9 \mathrm{mgC} \mathrm{m}^{-2} \mathrm{~h}^{-1}\right)$, or a boundary-layer average of $6.6 \times 10^{6}$ molec $\mathrm{cm}^{-3} \mathrm{~s}^{-1}$. These rates are within the range of previous MBO flux measurements at BFRS (Baker et al., 1999; Schade et al., 2000) and of values employed by other models (Perez et al., 2009; Steiner et al., 2007). Though our emissions estimates generally agree with other literature values, the standard emission parameterization does have limitations. Previous work at BFRS has shown that basal emission rates can vary with temperature history and other factors (Gray et al., 2003, 2006) and that tree-to-tree variability in emission rates can be substantial (Bouvier-Brown et al., 2009c).

Isoprene is not emitted in significant quantities from Ponderosa pine, Manzanita or Ceanothus (N. Bouvier-Brown, personal communication, 2009), but it can originate from less abundant vegetation within the forest stand and upwind, particularly Black Oak. Although direct measurements of above-canopy isoprene fluxes have not been conducted at BFRS, early isoprene gradient measurements and relaxed eddy accumulation observations in 1998 and 1999 indicated no significant emissions from the BFRS fetch (Dreyfus et al., 2002; Goldstein et al., 2001). Analysis of mixing ratio diurnal profiles at this site have determined that isoprene is primarily advected from a band of Oak located 30-40 km upwind (Dreyfus et al., 2002). The current construction of CAFE is unable to simultaneously reproduce the concentrations of isoprene and its main oxidation products, methyl vinyl ketone (MVK) and methacrolein (MACR), solely through our advection scheme. Thus, in addition to advecting isoprene at a rate of $1 \mathrm{ppbv} \mathrm{h}^{-1}$, we invoke a substantial emission rate of isoprene ( $\sim 40 \%$ of the MBO emissions). While local (e.g. $<500 \mathrm{~m}$ upwind) isoprene emissions are probably smaller than this, our isoprene emission rate is nearly identical to that used in the $4 \mathrm{~km} \times 4 \mathrm{~km}$ grid cell of a three-dimensional model that contains BFRS (Steiner et al., 2007). The vertical profile of isoprene, and potentially its oxidation products, will depend somewhat on the nature of its sources (i.e. emission vs. advection). A small set of in-canopy isoprene gradients measured near the end of the BEARPEX-2007 campaign (after our cool period) suggest that in-canopy isoprene mixing ratios can exceed abovecanopy values by as much as a factor of 2 (J. Gilman, personal communication, 2010), but it remains unclear if this gradient can be attributed to local emissions. We will note when this issue affects our conclusions.

Since modeled mixing ratios of locally-emitted BVOC are primarily a function of the rates of emission and chemical loss (assuming roughly homogenous upwind emissions and a chemical lifetime of a few hours), it is worthwhile to compare modeled and measured concentrations of these (Table 5). MBO mixing ratios are reproduced to within $6 \%$ during both hot and cool periods, suggesting that the radiation and temperature adjustments are accurate for MBO emissions. MCHAV and total MT are predicted to within $10 \%$ during the hot period but are under-predicted during the cool period by $60-70 \%$, while total SQT are over-predicted by $150 \%$ during the cool period. These errors could stem from the temperature corrections for emission rates, which become increasingly important at lower temperatures, or from deficiencies in modeled vertical mixing (note that the inlet for MT and SQT observations was moved from $1.5 \mathrm{~m}$ to $9.2 \mathrm{~m}$ between the hot and cool periods).

Even though total MT concentrations are well reproduced during the hot period, modeled terpene speciation differs from observations. The model generally under-predicts $\beta$ pinene and 3-carene and over-predicts myrcene, camphene, terpinolene, $\alpha$-terpinene and $\gamma$-terpinene (Table S2). Such discrepancies may arise from inaccurate estimates of emission speciation. Though we use the best estimates from leaflevel measurements (Bouvier-Brown et al., 2009c), terpene emissions are subject to plant physiological and environmental conditions that are not easily modeled. The relative terpene speciation has little impact on our conclusions regarding the chemical contribution to trace gas fluxes.

The terpene oxidation tracers MTOX and SQTOX show roughly the same seasonal trend as their VOC precursors (Table 5). Despite a fast deposition velocity, canopy-top concentrations of MTOX and SQTOX build up to 101 and $41 \mathrm{pptv}$, respectively, during the hot period. Many of the compounds represented by these tracers will contain alkenyl moieties and thus may still participate in oxidative chemistry. For both periods, near-surface MTOX and SQTOX gradients (not shown) match previous CAFE model results (Wolfe and Thornton, 2011).

In addition to the speciated single-height measurements, the BEARPEX-2007 dataset also includes vertical profiles of several classes of VOC acquired via proton-transfer mass spectrometry (PTR-MS). Details regarding instrumentation and measurement setup can be found elsewhere (BouvierBrown et al., 2009b; Holzinger et al., 2005). Figure 2 compares modeled BVOC profiles to four sets of PTR-MS measurements: total monoterpenes ( $\Sigma \mathrm{MT}$ ), MCHAV, the sum of MBO and isoprene and the sum of MVK and MACR. For clarity, observations and model results are presented from the 
Table 5. Model-measurement comparison of BVOC and peroxides. Model results are taken from the layer closest to the measurement height. Measurements are reported as the mean $\pm 1 \sigma$.

\begin{tabular}{lrrrr}
\hline \multirow{2}{*}{ Species } & Height/m & \multicolumn{2}{c}{ Concentrations/pptv } & \% Difference \\
\cline { 3 - 4 } & & Model & Meas & \\
\hline Hot & & & & \\
MBO & 6.4 & 3237 & $3182 \pm 1092$ & -2 \\
isoprene & 6.4 & 1627 & $1645 \pm 676$ & -1 \\
$\mathrm{MCHAV}$ & 1.5 & 81 & $79 \pm 13$ & +3 \\
$\mathrm{MT}$ & 1.5 & 491 & $538 \pm 46$ & -9 \\
$\mathrm{SQT}$ & 1.5 & 56 & $56 \pm 9$ & -0.4 \\
$\mathrm{MTOX}$ & 10 & 101 & - & - \\
$\mathrm{SQTOX}$ & 10 & 41 & - & - \\
$\mathrm{ISOPOOH}+\mathrm{IEPOX}^{\mathrm{b}}$ & 16.8 & 495 & $247 \pm 147$ & +100 \\
$\mathrm{H}_{2} \mathrm{O}_{2}$ & 16.8 & 856 & $884 \pm 91$ & -3 \\
& & & & \\
Cool & & & & \\
MBO & 6.4 & 659 & $623 \pm 261$ & +6 \\
isoprene & 6.4 & 251 & $211 \pm 71$ & +19 \\
$\mathrm{MCHAV}$ & 9.2 & 11 & $37 \pm 6$ & -71 \\
$\mathrm{MT}$ & 9.2 & 78 & $213 \pm 38$ & -63 \\
$\mathrm{SQT}$ & 9.2 & 15 & $6 \pm 2$ & +146 \\
$\mathrm{MTOX}$ & 10 & 23 & - & - \\
SQTOX & 10 & 18 & - & - \\
ISOPOOH + IEPOX & 16.8 & 27 & $55 \pm 10$ & -51 \\
$\mathrm{H}_{2} \mathrm{O}_{2}$ & 16.8 & 531 & $634 \pm 54$ & -16 \\
\hline
\end{tabular}

a Calculated as $100 *$ (Model - Meas)/Meas.

b Sum of four isomers (ISOPAOOH + ISOPBOOH + ISOPCOOH + ISOPDOOH) and the isoprene dihydroxyepoxide IEPOX.

hot period only and have been normalized to their canopy-top values; modeled and measured profiles exhibit similar normalized gradients for both the hot and cool periods. Modelmeasurement agreement is generally quite good, though the model under-predicts gradients of $\Sigma \mathrm{MT}$ and MCHAV in the lower canopy. Potential explanations include an unidentified emission source near the ground such as decaying pine needles, as suggested by Stroud et al. (2005), or inefficient turbulent mixing in the lower canopy, which could lead to a buildup of BVOC emitted from the understory. The existence of a "weakly coupled" layer near the ground - or at least slower vertical mixing than modeled in CAFE - would also be consistent with model-measurement comparisons of $\mathrm{NO}_{2}$ and PAN gradients (see Sect. 3.5). A lack of wind penetration into the deep canopy would seem the most likely cause (as opposed to a thermal inversion). To test this hypothesis, we conducted a simple sensitivity test where we uniformly reduced the eddy diffusivities (K-values) below $z / h=0.5$ $(5 \mathrm{~m})$. Results from this test (not shown) reveal that reducing $\mathrm{K}$-values by a factor of three greatly improves agreement between modeled and measured $\Sigma \mathrm{MT}$ gradients but increases the canopy residence time to $5 \mathrm{~min}$.
The modeled $\mathrm{MBO}+$ isoprene gradient agrees fairly well with observations, increasing $\sim 20 \%$ between canopy top and the forest floor. This profile would be less steep if isoprene were primarily advected in CAFE, as the isoprene profile would then be more vertical and observed isoprene mixing ratios are $25-33 \%$ of $\mathrm{MBO}+$ isoprene at noon (Table 5). The mean observed $\mathrm{MBO}+$ isoprene mixing ratio at $z / h=0.15$ $(1.5 \mathrm{~m})$ is consistently $15 \%$ lower than that at $6.1 \mathrm{~m}$ (Fig. 2c). This feature persists even in individual 30-min gradient observations. As MBO (and isoprene, in CAFE) are primarily emitted from the overstory, this feature would be consistent with a depositional sink of MBO and isoprene near the ground (Stroud et al., 2005).

Profiles of the sum of MVK and MACR, which are firstgeneration oxidation products of isoprene, are fairly vertical in both the model and measurement (Fig. 2d), though the modeled profile shows a slight enhancement in the canopy due to production. Previous studies have suggested that MVK and MACR should also deposit to the canopy/ground with a deposition velocity similar to that of ozone (Stroud et al., 2005; Zhang et al., 2003; Karl et al., 2010). We do not include deposition of these compounds in CAFE since the observed mean profiles do not suggest strong deposition of oxidized VOC in this forest. 

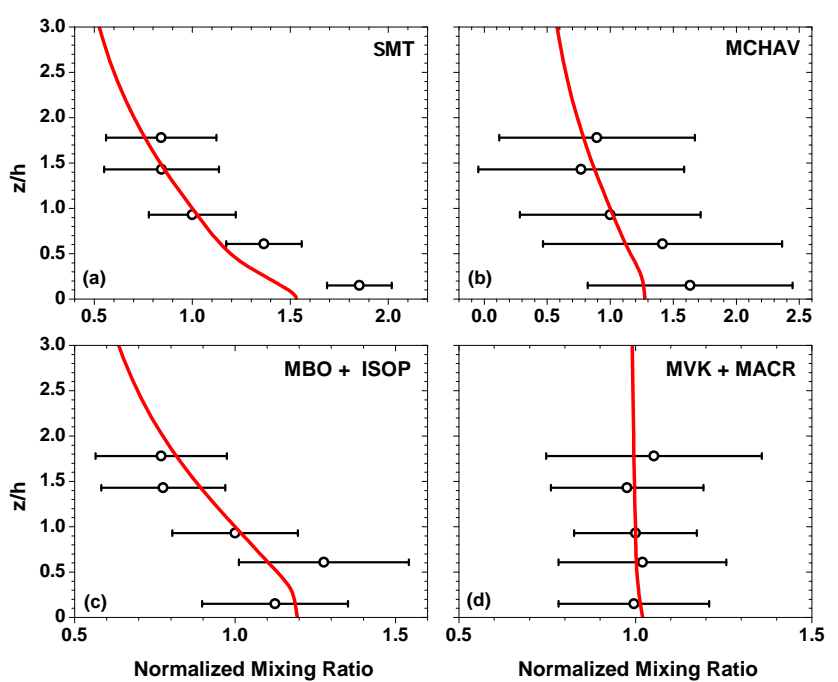

Fig. 2. Comparison of measured and modeled gradients of (a) total monoterpenes, (b) methyl chavicol, (c) the sum of MBO and isoprene and (d) the sum of MVK and MACR. Both modeled and measured values are taken from the hot period. PTR-MS observations represent the mean of six 5-min-averaged measurements at each height and are normalized by the $9.3 \mathrm{~m}$ mixing ratios; error bars represent standard deviations. Model profiles are normalized to their canopy-top values $(z / h=1)$.

The hydroxyl radical $(\mathrm{OH})$ is the primary daytime oxidant for most VOC in the troposphere. OH reactivity $\left(\tau_{\mathrm{OH}}^{-1}\right)$, or inverse $\mathrm{OH}$ lifetime, is defined as the sum of all $\mathrm{OH}$ loss rates divided by the $\mathrm{OH}$ concentration:

$\tau_{\mathrm{OH}}^{-1}=\sum_{i} k_{i} C_{i}$

Here, $k_{i}$ is the second-order rate constant for reaction of $\mathrm{OH}$ with species $i$ having concentration $C_{i}$. OH reactivity was measured directly during BEARPEX-2007 following the approach described in Mao et al. (2009) and is useful for constraining both VOC inventories and steady-state calculations of oxidant concentrations. Figure 3 compares model calculations of $\tau_{\mathrm{OH}}^{-1}$ with observed values. During the hot period, modeled $\left(12.3 \mathrm{~s}^{-1}\right)$ and measured $\left(12.4 \pm 2.0 \mathrm{~s}^{-1}\right) \tau_{\mathrm{OH}}^{-1}$ are in excellent agreement. About $63 \%$ of the modeled $\tau_{\mathrm{OH}}^{-1}$ is attributed to primary BVOC, with another $22 \%$ due to reactions with $\mathrm{HCHO}, \mathrm{CO}, \mathrm{CH}_{4}$ and the first-generation oxidation products of isoprene (MVK and MACR) and MBO (IBUTALOH and $\mathrm{HOCH}_{2} \mathrm{CHO}$ ). The remaining $15 \%$ ("other") includes $\sim 300$ reactions, each of which comprise $<1 \%$ of $\tau_{\mathrm{OH}}^{-1}$. During the cool period, modeled $\tau_{\mathrm{OH}}^{-1}\left(3.6 \mathrm{~s}^{-1}\right)$ is lower than observations $\left(6.8 \pm 1.2 \mathrm{~s}^{-1}\right)$ by almost a factor of 2 . Model underestimates of MT and MCHAV mixing ratios during this period are not sufficient to explain this discrepancy, and the nature of this missing $\mathrm{OH}$ reactivity remains unclear. These results, including the missing $\mathrm{OH}$ reactivity during the cold period, are consistent with observationally-

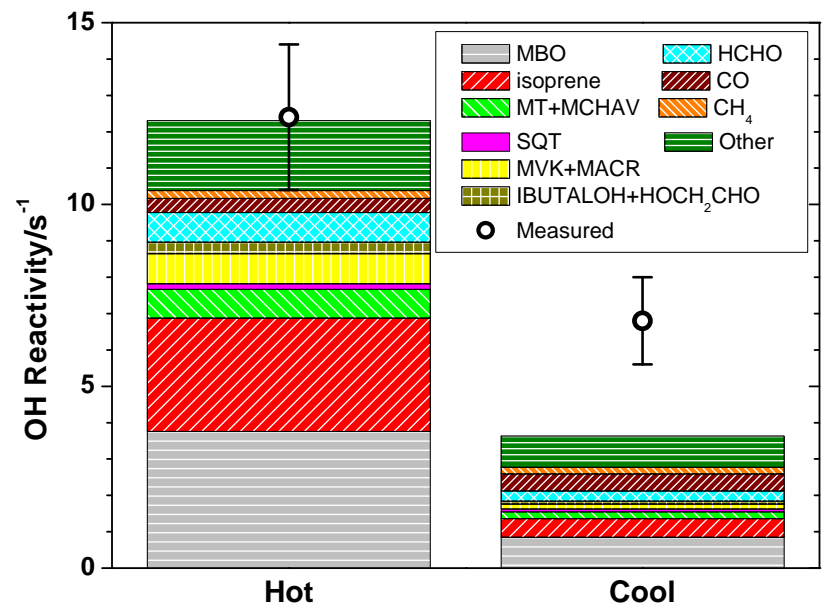

Fig. 3. Modeled $\mathrm{OH}$ reactivity for the hot (left) and cool (right) periods at $z / h=1(10 \mathrm{~m})$. The "other" category contains contributions from $\sim 300$ reactions. Open circles and error bars denote measured bulk $\mathrm{OH}$ reactivity (mean $\pm 1 \sigma)$.

constrained bottom-up estimates of $\tau_{\mathrm{OH}}^{-1}$ (Mao et al., 2008). The latter study also demonstrated that measured anthropogenic VOC are a negligibly small contribution to $\tau_{\mathrm{OH}}^{-1}$ at BFRS.

Some of the missing $\mathrm{OH}$ reactivity might be attributed to a missing source of formaldehyde (HCHO). During the cool period, CAFE predicts HCHO mixing ratios of $\sim 1.3$ ppbv, while measurements indicate a noontime mean of $12.5 \pm 4.0 \mathrm{ppbv}$ (Table S2); HCHO observations were not available during the hot period. Increasing $\mathrm{HCHO}$ mixing ratios to match observations (by raising the initial/advection $\mathrm{HCHO}$ concentrations) brings the modeled $\mathrm{OH}$ reactivity to $6 \mathrm{~s}^{-1}$, which is within the range of observations. Maintaining this level of $\mathrm{HCHO}$ in the model leads to a $50 \%$ overprediction of hydroperoxy radical $\left(\mathrm{HO}_{2}\right)$ and hydrogen peroxide $\left(\mathrm{H}_{2} \mathrm{O}_{2}\right)$; OH increases by $15 \%$. The sources of the elevated $\mathrm{HCHO}$ mixing ratios observed during the cold period are presently unknown but may be linked to oxidation of yet-unidentified reactive BVOC inferred from previous observations at BFRS (Choi et al., 2010; Holzinger et al., 2005). As constraining HCHO to measured values does not noticeably perturb the exchange velocities of key species in the model and because of a lack of measurements during the hot period, we retain the CAFE-predicted $\mathrm{HCHO}$ values for consistency between the two periods. A detailed evaluation of BEARPEX-2007 HCHO observations may be found elsewhere (Choi et al., 2010).

\section{$3.2 \mathrm{RO}_{\mathrm{x}}$}

Cycling of hydrogen oxide radicals is driven by VOC and nitric oxide (NO). The sequence begins with reaction of $\mathrm{OH}$ and VOC to produce an organic peroxy radical $\left(\mathrm{RO}_{2}\right)$. Subsequent reaction of $\mathrm{RO}_{2}$ with $\mathrm{NO}$ produces $\mathrm{NO}_{2}$ and an 
alkoxy radical (RO). Typically, the latter reacts with $\mathrm{O}_{2}$ to yield a hydroperoxy radical $\left(\mathrm{HO}_{2}\right)$ and a closed-shell aldehyde or ketone. In the CAFE mechanism, the latter two processes are combined. $\mathrm{OH}$ is regenerated upon reaction of $\mathrm{HO}_{2}$ with $\mathrm{NO}$ to form $\mathrm{NO}_{2}$.

$$
\begin{aligned}
& \mathrm{OH}+\mathrm{VOC} \rightarrow \mathrm{RO}_{2}+\mathrm{H}_{2} \mathrm{O} \\
& \mathrm{RO}_{2}+\mathrm{NO} \rightarrow \mathrm{NO}_{2}+\mathrm{HO}_{2}+\text { carbonyls } \\
& \mathrm{HO}_{2}+\mathrm{NO} \rightarrow \mathrm{OH}+\mathrm{NO}_{2}
\end{aligned}
$$

As a result of this cycling, we define the chemical families $\mathrm{HO}_{\mathrm{x}}=\mathrm{OH}+\mathrm{HO}_{2}, \mathrm{RO}_{\mathrm{x}}=\mathrm{HO}_{\mathrm{x}}+\mathrm{RO}_{2}$ and $\mathrm{NO}_{\mathrm{x}}=\mathrm{NO}+\mathrm{NO}_{2}$. Partitioning within the $\mathrm{RO}_{\mathrm{x}}$ and $\mathrm{NO}_{\mathrm{x}}$ families is thus coupled by VOC abundance and reactivity with $\mathrm{OH}$. Moreover, cross-reactions between $\mathrm{RO}_{\mathrm{x}}$ and $\mathrm{NO}_{\mathrm{x}}$ produce longer-lived reactive nitrogen species, the forest-atmosphere exchange of which can be sensitive to vertical gradients in this chemistry.

Figure 4 depicts modeled profiles of $\mathrm{OH}, \mathrm{HO}_{2}$ and $\mathrm{RO}_{2}$ radicals. For each period, the model was run both with and without the enhanced $\mathrm{OH}$ recycling mechanism discussed in Sect. 2.2. Both periods show small positive (increasing with height) in-canopy $\mathrm{HO}_{2}$ gradients of $\sim 5 \%$. The $\mathrm{OH}$ mixing ratio increases by $\sim 10 \%$ between the ground and the top of the canopy in the hot period and by $\sim 40 \%$ in the cool period. The relative gradients are mostly unaffected by the enhanced $\mathrm{OH}-\mathrm{recycling}$ mechanism, though $\mathrm{OH}$ does exhibit a slight bulge maximizing at $z / h=1.4$ during the hot period with enhanced $\mathrm{OH}$ recycling, and $\mathrm{RO}_{2}$ is $\sim 20 \%$ higher within the canopy than above for the same scenario. Enhanced $\mathrm{OH}$ recycling is required for replicating observations during the hot period. Excluding this mechanism leads to under-prediction of noontime $\mathrm{OH}$ by a factor of 6 and of $\mathrm{HO}_{2}$ by $\sim 25 \% ; \mathrm{RO}_{2}$ was not measured. Preliminary data from BEARPEX-2009 suggests measured $\mathrm{OH}$ mixing ratios from the 2007 campaign may be overestimated, perhaps by as much as a factor of 2 (Brune et al., 2010). Even in the face of such a systematic error, modeled values would still be too low by a factor of three and we would still require enhanced $\mathrm{OH}$ recycling.

Model-measurement mismatch of $\mathrm{OH}$ is a recurrent issue in investigations of $\mathrm{RO}_{\mathrm{x}}$ chemistry under conditions where $\mathrm{BVOC}$ such as isoprene are a dominant source of $\mathrm{RO}_{2}$ (Hofzumahaus et al., 2009; Lelieveld et al., 2008; Thornton et al., 2002; Ren et al., 2008; Martinez et al., 2003; Tan et al., 2001). Many of these studies, and others, have proposed mechanisms to augment radical production and propagation, including reduction in the formation rate of isoprene-derived organic hydroperoxides and/or enhancement of their photolysis rates (Thornton et al., 2002), additional production of $\mathrm{OH}$ during reactions of isoprene-derived first-generation $\mathrm{RO}_{2}$ with $\mathrm{HO}_{2}$ (Lelieveld et al., 2008; Thornton et al., 2002), inclusion of an unknown species " $\mathrm{X}$ " that reacts with $\mathrm{RO}_{2}$ and $\mathrm{HO}_{2}$ with the same efficacy as $\mathrm{NO}$ (Hofzumahaus et al., 2009), and $\mathrm{RO}_{2}$ isomerization and decomposition (Peeters et al., 2009; Da Silva et al., 2010). We tested each of these
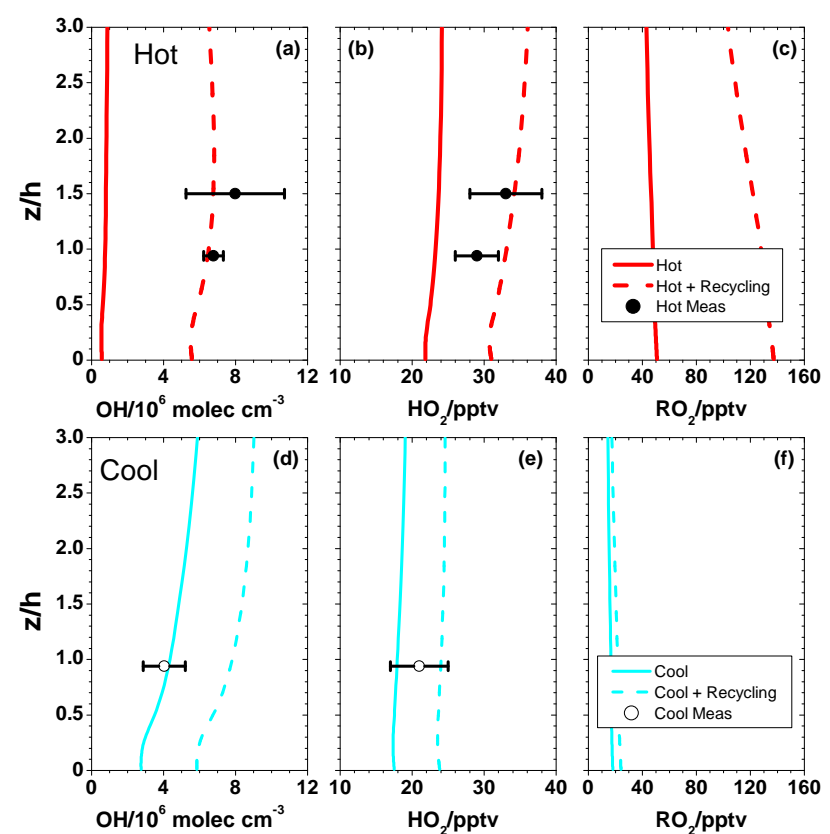

Fig. 4. Profiles of modeled $\mathrm{OH}, \mathrm{HO}_{2}$ and $\mathrm{RO}_{2}$ mixing ratios during the hot $(\mathbf{a}-\mathbf{c})$ and cool $(\mathbf{d}-\mathbf{f})$ periods. Solid lines are results from model runs without the enhanced $\mathrm{OH}$ recycling mechanism (Sect. 3.2), while dashed lines represent model runs with $\mathrm{OH}$ recycling on. Filled and open circles represent observations (mean $\pm 1 \sigma$ ) for the hot and cool periods, respectively.

mechanisms separately in CAFE, but found that no single mechanism could adequately reproduce observed $\mathrm{HO}_{\mathrm{x}}$ partitioning and abundance simultaneously with other key indicators, such as oxidized VOC abundance and speciation. For example, incorporation of the isoprene hydroxyperoxy radical isomerization/decomposition mechanism - as implemented in Stavrakou et al. (2010) with an $\mathrm{OH}$ yield of 3 from the photolysis of hydroxyperoxy aldehyde products leads to a $30 \%$ over-prediction of $\mathrm{HO}_{2}$ but a factor of three under-prediction of $\mathrm{OH}$ in the hot period. Furthermore, the postulated isomerization requires an allylic radical, thus firstgeneration MBO-derived peroxy radicals will not undergo analogous reactions.

Using measured $\mathrm{OH}$ reactivity and concentrations, and assuming $\mathrm{OH}$ is in steady state (i.e. production equals loss), we estimate an observationally-constrained gross $\mathrm{OH}$ production rate $\left(P_{\mathrm{OH}}\right)$ of $\sim 4 \mathrm{pptv} \mathrm{s}^{-1}$ for noontime conditions during the hot period. Without $\mathrm{OH}$ recycling, modeled $P_{\mathrm{OH}}$ for the hot period is $\sim 0.7 \mathrm{pptv} \mathrm{s}^{-1}$ and is mainly driven by $\mathrm{O}_{3}$ photolysis and reaction of $\mathrm{HO}_{2}$ with NO. As the model accurately reproduces measured $\mathrm{OH}$ reactivity during the hot period (Fig. 3), we conclude that the under-prediction of $\mathrm{OH}$ stems from inefficient recycling and/or excessive termination by $\mathrm{RO}_{\mathrm{x}}$ cross-reactions. Inclusion of the tuned $\mathrm{OH}$ recycling mechanism (Table 3 ) brings modeled $\mathrm{OH}$ and $\mathrm{HO}_{2}$ to within the range of observations and increases $\mathrm{RO}_{2}$ by a 
factor of $\sim 2.5 . \mathrm{HO}_{2}$ is mostly conserved in the enhanced $\mathrm{OH}$-recycling mechanism, thus the increase in modeled $\mathrm{HO}_{2}$ is primarily due to a larger source from $\mathrm{RO}_{2}$ reactions with NO.

Another potentially important $\mathrm{OH}$ source is ozonolysis of highly-reactive VOC not included in our emission inventory (Goldstein et al., 2004; Holzinger et al., 2005; Faloona et al., 2001). Holzinger et al. (2005) estimated that an average incanopy $\mathrm{O}_{3}$ reaction rate of $5.25 \times 10^{8}$ molecules $\mathrm{cm}^{-3} \mathrm{~s}^{-1}$, or $25 \mathrm{pptv} \mathrm{s}^{-1}$, would be required to sustain the chemical contribution to in-canopy ozone fluxes inferred by previous studies (Goldstein et al., 2004; Holzinger et al., 2005; Kurpius and Goldstein, 2003). Given that our missing $P_{\mathrm{OH}}$ is $\sim 3.3$ pptv s$^{-1}$, an average $\mathrm{OH}$ yield of $13 \%$ from these reactions would be sufficient to sustain measured $\mathrm{OH}$ levels in the canopy. The resulting $\mathrm{OH}$ concentration from such a source, however, would lead to model overestimates of $\mathrm{HO}_{2}$ and likely $\mathrm{RO}_{2}$. That is, such a source would still imply an incomplete understanding of $\mathrm{RO}_{2} / \mathrm{HO}_{2}$ chemistry.

Our enhanced $\mathrm{OH}$-recycling mechanism is similar to a blending of those proposed by Lelieveld et al. (2008) and Peeters et al. (2009). Our mechanism ties $\mathrm{OH}$ recycling to $\mathrm{RO}_{2}+\mathrm{HO}_{2}$ reactions, but it is an additional process in competition with the peroxide-forming channel. The mechanism also simultaneously converts the primary $\mathrm{MBO}$ and isoprenederived $\mathrm{RO}_{2}$ radicals into the relevant oxidation products as if passing through the respective RO radicals. Essentially, it is an enhanced $\mathrm{RO}_{2}$ decomposition that yields $\mathrm{OH}$ and oxidized VOC but has little net effect on $\mathrm{HO}_{2}$. Failure to incorporate $\mathrm{RO}_{2}$ destruction in the enhanced $\mathrm{OH}$ recycling mechanism leads to unrealistic $\mathrm{RO}_{2}$ concentrations ( $>300 \mathrm{pptv}$ ), which in turn results in overestimation of several oxidation products - such as glyoxal and acetone - and unreasonably low $\mathrm{NO} / \mathrm{NO}_{2}$ ratios. With our enhanced $\mathrm{OH}$ recycling mechanism, model results are consistent with $\mathrm{RO}_{2}$ and $\mathrm{NO} / \mathrm{NO}_{2}$ values derived from observationally-constrained steady-state calculations for this site (LaFranchi et al., 2009; Day et al., 2008) and with observations of total peroxy radicals at other forested locations (Cantrell et al., 1992; Qi et al., 2005). Furthermore, small-chain BVOC oxidation products agree reasonably well with BEARPEX-2007 observations (Table S2), though mixing ratios of these are also influenced by advection. Previous studies at BFRS have provided evidence for a temperature-dependent $\mathrm{HO}_{\mathrm{x}}$ source (Day et al., 2008; Farmer and Cohen, 2008). Our enhanced recycling mechanism is also consistent with this observational evidence as the $\mathrm{OH}$ production rate decreases with decreasing temperature by virtue of its reliance on $\mathrm{RO}_{2}$ formed from BVOC.

In contrast to the hot period, modeled $\mathrm{OH}$ agrees with observations during the cool period without the need for additional $\mathrm{OH}$ recycling, while $\mathrm{HO}_{2}$ is somewhat underpredicted. As CAFE underestimates measured $\mathrm{OH}$ reactivity by a factor of 2 during the cool period, however, this agreement is likely artificial. Incorporating enhanced $\mathrm{OH}$ recycling during the cool period leads to overestimation of
$\mathrm{OH}$ by a factor of $\sim 2$. Thus, by constraining modeled $\mathrm{OH}$ reactivity to the measured value and assuming the missing reactivity is caused by a non-methane hydrocarbon that is not $\mathrm{MBO}$ or isoprene, model-measurement agreement of $\mathrm{OH}$ concentrations during the cool period can be achieved when employing the enhanced recycling mechanism. As this result ultimately depends on the nature of the missing reactivity, and as $\mathrm{OH}, \mathrm{HO}_{2}$, and $\mathrm{RO}_{2}$ abundances are reasonably predicted by CAFE during the cool period without the recycling mechanism, we leave this issue for future investigation.

\subsection{Peroxides}

In high- $\mathrm{RO}_{\mathrm{x}}$ and high-VOC environments, peroxide formation is considered a key radical termination step:

$\mathrm{HO}_{2}+\mathrm{HO}_{2} \rightarrow \mathrm{H}_{2} \mathrm{O}_{2}+\mathrm{O}_{2}$

$\mathrm{RO}_{2}+\mathrm{HO}_{2} \rightarrow \mathrm{ROOH}+\mathrm{O}_{2}$

In the case of isoprene oxidation, further reaction of firstgeneration $\mathrm{ROOH}$ with $\mathrm{OH}$ can generate dihydroxyepoxides (Paulot et al., 2009c) or carbonyl-containing oxidized VOC:

$\mathrm{ROOH}+\mathrm{OH} \rightarrow \mathrm{IEPOX}+\mathrm{OH}$

$\mathrm{ROOH}+\mathrm{OH} \rightarrow \mathrm{oVOC}+\mathrm{OH}$

Comparison of modeled and measured peroxides/epoxides thus provides an additional indirect check on $\mathrm{RO}_{\mathrm{x}}$ abundance and chemistry in CAFE. BEARPEX-2007 observations include both hydrogen peroxide $\left(\mathrm{H}_{2} \mathrm{O}_{2}\right)$ and the sum of firstgeneration isoprene hydroxyhydroperoxides (ISOPOOH, see Appendix A) and isoprene dihydroxyepoxides (IEPOX).

As shown in Table 5, ISOPOOH+IEPOX is over-predicted by a factor of 2 during the hot period, suggesting that production is too fast and/or losses - which include reaction with $\mathrm{OH}$, photolysis and deposition - are too slow. Production of ISOPOOH depends on mixing ratios of $\mathrm{HO}_{2}$ and first-generation isoprene-derived $\mathrm{RO}_{2}$. Observational constraints are only available for the former, thus we cannot rule out a model overestimation of isoprene- $\mathrm{RO}_{2}$, though this seems unlikely. Modeled $\mathrm{OH}$ and isoprene $\left(\mathrm{RO}_{2}\right.$ precursors) agree with measurements, and the over-prediction persists even without our enhanced OH-recycling mechanism - when $\mathrm{OH}$ and $\mathrm{RO}_{2}$ concentrations are substantially lower. Isomerization of isoprene- $\mathrm{RO}_{2}$ (Peeters et al., 2009) could mitigate production of ISOPOOH; however, as we noted in Sect. 3.2, this mechanism also leads to over-prediction of $\mathrm{HO}_{2}$ in our model.

It is more probable that modeled sinks of ISOPOOH and/or IEPOX are too slow. The lifetimes of ISOPOOH against $\mathrm{OH}$ via Reactions (15) and (16) are $0.7 \mathrm{~h}$ and $8.5 \mathrm{~h}$, respectively. Thus, $92 \%$ of this reaction proceeds through the epoxide-forming channel, and IEPOX comprises $57 \%$ of the ISOPOOH+IEPOX family during the hot period. IEPOX reacts with $\mathrm{OH}$ with a lifetime of $\sim 3 \mathrm{~h}$ using the recommended 
rate constant from Paulot et al. (2009c). A factor of 10 increase in the rate constants for reaction of $\mathrm{OH}$ with either ISOPOOH (via Reaction 16) or IEPOX reduces the model over-estimate to $29 \%$ or $17 \%$, respectively. Deposition of ISOPOOH is currently implemented with a deposition velocity of $\sim 1.6 \mathrm{~cm} \mathrm{~s}^{-1}$ (Hall and Claiborn, 1997), while IEPOX is forced to deposit at the aerodynamic limit. An increase in deposition of ISOPOOH would reduce the model overestimate but is not a sufficient explanation on its own. Faster photolysis of ISOPOOH is also not likely a viable solution, as the rate for this process is ten times slower than reaction with $\mathrm{OH}$ in the base scenario. One potentially important sink for IEPOX is uptake to particles, which is not currently included in CAFE. Optimal model-measurement agreement during the hot period - assuming rates for other sinks are reasonably estimated - would require $88 \%$ of IEPOX be lost to particles.

In contrast to the hot period, ISOPOOH + IEPOX is underpredicted by $51 \%$ during the cool period. This may indicate an under-prediction of isoprene- $\mathrm{RO}_{2}$ for this scenario, though we note again that both isoprene and $\mathrm{OH}$ are within the range of observations. At present, it is difficult to reconcile the large differences in model-measurement agreement between the two scenarios. One potential explanation may lie in advection. These compounds have been assigned initial/advection concentrations of 0 to simplify comparison to observations, but it is very likely that their "advection concentrations" are higher than we ascribe due to the upwind isoprene source. Increasing advection would improve modelmeasurement agreement during the cool period but degrade it during the hot period; thus, an increased advection source must also be coupled with a temperature-dependent sink.

Modeled $\mathrm{H}_{2} \mathrm{O}_{2}$ concentrations agree with observations to within $3 \%$ and $16 \%$ for the hot and cold period, respectively. As noted in the companion paper (Wolfe and Thornton, 2011), CAFE forces $\mathrm{H}_{2} \mathrm{O}_{2}$ to deposit at the aerodynamic limit by setting the effective Henry's Law coefficient $(H *)$ used in the deposition parameterization to $1 \times 10^{14} \mathrm{M} \mathrm{atm}^{-1}$. This yields above-canopy exchange velocities of -4 to $-5 \mathrm{~cm} \mathrm{~s}^{-1}$. If we instead use the literaturerecommended $\mathrm{H}^{*}$ of $1 \times 10^{5} \mathrm{M} \mathrm{atm}^{-1}$ (Seinfeld and Pandis, 2006), $\mathrm{H}_{2} \mathrm{O}_{2}$ concentrations are over-predicted by as much as $50 \%$. Though $\mathrm{H}_{2} \mathrm{O}_{2}$ mixing ratios are somewhat dependent on our choice of initial/advection concentrations (Table 4), this finding is consistent with previous field studies that have reported diffusion-limited $\mathrm{H}_{2} \mathrm{O}_{2}$ deposition over forests, much faster than predicted by the Wesely (1989) parameterization (Ganzeveld et al., 2006; Hall and Claiborn, 1997). Recent measurements at BFRS also suggest transportlimited $\mathrm{H}_{2} \mathrm{O}_{2}$ deposition (Paulot et al., 2009a), a finding supported by our model results. Our choice to increase $H *$ to match the observed $\mathrm{H}_{2} \mathrm{O}_{2}$ exchange velocity does not necessarily imply that the molecular mechanism controlling $\mathrm{H}_{2} \mathrm{O}_{2}$ surface loss is related to solubility; rather, we view the cuticular resistance (which is controlled partly by $H *$ ) as a tunable parameter that could represent any number of yetundiscovered chemical or physical uptake processes.

\subsection{Ozone}

Deposition of $\mathrm{O}_{3}$ is a major concern due to its impact on plant tissues (Darrall, 1989), which can reduce carbon sequestration (Sitch et al., 2007), enhance emissions of oxidized VOC (Karl et al., 2005; Schade and Goldstein, 2002) and alter uptake of other gas-phase species (Karl et al., 2010). As a terminal sink, deposition also influences the lifetime of gas-phase $\mathrm{O}_{3}$ near the surface. Furthermore, ozonolysis of reactive BVOC can produce $\mathrm{OH}$ and oxygenated VOC within and immediately above the canopy (Ciccioli et al., 1999; Holzinger et al., 2005), stimulating gas-phase oxidative chemistry and growth of secondary organic aerosol ( $\mathrm{Li}$ et al., 2011; Paulson et al., 1998). This chemistry may be fast enough to alter the net forest-atmosphere flux of both $\mathrm{O}_{3}$ and BVOC (Goldstein et al., 2004; Kurpius and Goldstein, 2003; Stroud et al., 2005). Thus, characterization of the underlying mechanisms of forest-atmosphere $\mathrm{O}_{3}$ exchange is critical for assessing both $\mathrm{O}_{3}$-induced ecosystem damage and our understanding of emissions and chemistry in this environment.

Figure 5 compares model and measured $\mathrm{O}_{3}$ concentrations, fluxes and exchange velocities. Mixing ratios agree reasonably well, decreasing slightly with height in the canopy region. Modeled downward (negative) fluxes and exchange velocities fall within the variability of observations but tend to under-predict mean values by $\sim 20 \%$ for both periods. CAFE successfully predicts the observed $20 \%$ increase in $\mathrm{O}_{3}$ fluxes between the hot and cool period, which is due to an increase in stomatal conductance accompanying the reduced vapor pressure deficit and temperature (Table 2). This behavior is counter to the generally-positive correlation between temperature and $\mathrm{O}_{3}$ fluxes observed on longer timescales at BFRS but is within the variability of measured $\mathrm{O}_{3}$ fluxes from a 6-yr dataset (Fares et al., 2010a).

Previous work at BFRS has provided evidence that both deposition (stomatal and non-stomatal uptake) and in-canopy reactions with biogenic emissions can influence $\mathrm{O}_{3}$ fluxes (Goldstein et al., 2004; Kurpius and Goldstein, 2003; Fares et al., 2010a). It is thus prudent to examine all processes contributing to $\mathrm{O}_{3}$ fluxes, defined by the various terms in the mass balance equation (Eq. 1). Figure 6a shows verticallyresolved instantaneous rates for all processes during the hot period. The model predicts that deposition is the dominant process within the canopy region. Other rates are small but consistent with expected chemical behavior, which derives primarily from the $\mathrm{NO}_{\mathrm{x}}-\mathrm{O}_{3}$ equilibrium:

$$
\begin{aligned}
& \mathrm{NO}_{2} \stackrel{h v}{\longrightarrow} \mathrm{O}\left({ }^{3} \mathrm{P}\right)+\mathrm{NO} \\
& \mathrm{O}\left({ }^{3} \mathrm{P}\right)+\mathrm{O}_{2} \rightarrow \mathrm{O}_{3} \\
& \mathrm{NO}+\mathrm{O}_{3} \rightarrow \mathrm{NO}_{2}+\mathrm{O}_{2}
\end{aligned}
$$



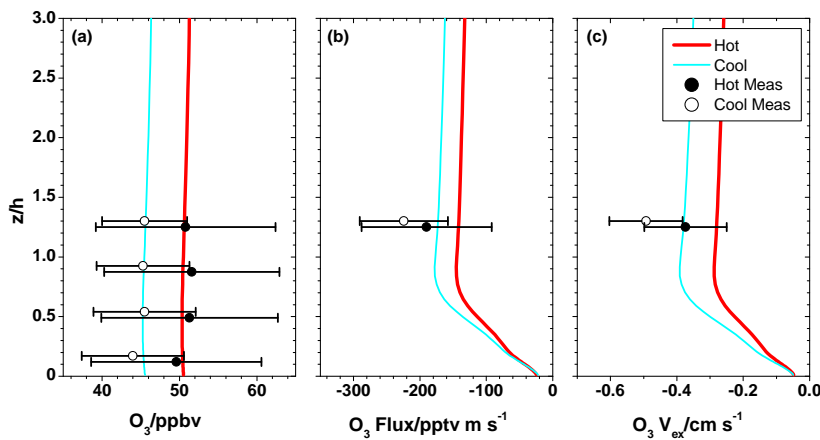

Fig. 5. Profiles of modeled ozone (a) mixing ratios, (b) fluxes and (c) exchange velocities for the hot and cool periods. Filled and open circles represent observations (mean \pm standard deviation) for the hot and cool periods, respectively. Cool period observations are offset on the y-axis for clarity. To convert $\mathrm{O}_{3}$ fluxes from chemical units (pptv m s${ }^{-1}$ ) to depositional units $\left(\mu \mathrm{mol} \mathrm{m} \mathrm{m}^{-2} \mathrm{~h}^{-1}\right.$ ), multiply by 0.125 .

Gross chemical $\mathrm{O}_{3}$ production tracks light attenuation in the canopy, as it is rate-limited by $\mathrm{NO}_{2}$ photolysis. Ozone photolysis controls gross chemical loss in the top half of the canopy, while reaction with soil-emitted NO dominates near the ground. The net chemical tendency $(P+L)$ changes sign halfway through the canopy. These results are consistent with those from other canopy models (Stroud et al., 2005). Contributions from advection $(A)$ and storage $(\partial C / \partial t)$ are small.

Rearrangement and integration of Eq. (1) shows that the vertical flux at any height, $F(z)$, is the sum of the ground-up integrals of the rate of each process:

$$
\begin{aligned}
F(z) & =\underbrace{\int_{0}^{z}[E(z)+D(z)] d z}_{\text {Surf }} \\
& +\underbrace{\int_{0}^{z}[P(z)+L(z)+A(z)-\partial C(z) / \partial t] d z}_{\text {Chem }}
\end{aligned}
$$

Here, we group contributions into surface and "chemical" processes (for $\mathrm{O}_{3}, E(z)=0$ ); these groups could also be thought of as "heterogeneous" and "gas phase." The integral over height of $\partial C / \partial t$ (the last term) is, by definition, the "storage" term employed in interpretation of flux observations (Rummel et al., 2007; Wolfe et al., 2009). Calculation of fluxes by this method yields the same values as those computed via Eq. (6), and normalization of each term by the modeled mixing ratio at any height gives the corresponding component of the exchange velocity. CAFE predicts that surface deposition controls the vertical flux of ozone (Fig. 6b), with chemistry inducing a slight positive slope on the $\mathrm{O}_{3}$ exchange velocity profile above the canopy; the model yields similar results for the cool period. At face value, this result appears to refute previous claims of a substantial chemical
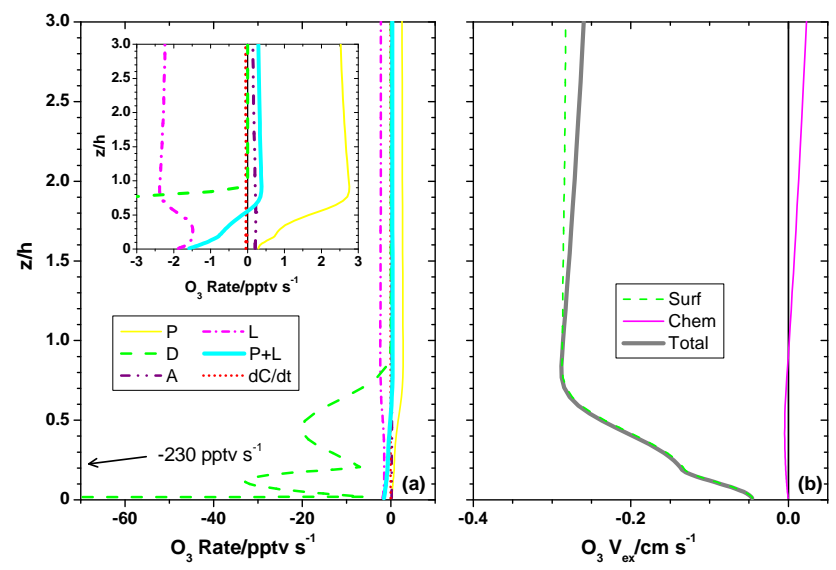

Fig. 6. (a) Modeled profiles of components of the instantaneous rates of change for ozone during the hot period. Contributions include chemical production (yellow solid line), chemical loss (magenta dash-dotted line), deposition (green dashed line), advection (purple dash-dot-dotted line) and storage (red dotted line). Also shown is the sum of chemical production and loss (thick cyan line). Ground deposition extends beyond the scale $\left(-230\right.$ pptv s $\left.^{-1}\right)$. The inset provides a zoomed-in view of the same model results. (b) Contributions to modeled ozone exchange velocity profile for the hot period, including surface (green dashed line) and chemical (magenta solid line) processes, as well as the net exchange velocity (thick gray line).

ozone flux at BFRS; however, as discussed below, modeled ozone fluxes in CAFE are subject to potentially significant uncertainties in non-stomatal deposition and reactive BVOC emissions.

Since deposition dominates the modeled $\mathrm{O}_{3}$ exchange, it is prudent to examine the contribution of various parameterized deposition pathways as enumerated in Table 6. Stomatal uptake, which is constrained by independent calculations based on observed latent heat fluxes (Wolfe and Thornton, 2011), accounts for $46 \%$ and $59 \%$ of the modeled exchange during the hot and cool periods, respectively. Non-stomatal deposition, which includes losses to both leaf cuticles and the ground, comprises the remaining 54\% and $41 \%$. Though the inclusion of non-stomatal deposition brings modeled ozone exchange velocities to within $24 \%$ and $20 \%$ of measured values, this agreement may be artificial as the true magnitude of non-stomatal deposition is not known. Constraints for nonstomatal deposition in CAFE are taken from a "big leaf" resistance model (Zhang et al., 2002, 2003) that assumes similar values across a fairly wide swath of ecosystems, and unlike the stomatal component, there is no simple way to validate this parameterization against observations. The possible influence of intra-canopy BVOC chemistry on observed above-canopy $\mathrm{O}_{3}$ fluxes was not considered during the development of these parameterizations, thus the resulting nonstomatal deposition rates may be artificially high. Leaf and branch-level enclosure experiments have observed negligible 
Table 6. Contributions to modeled ozone and PAN exchange velocities $\left(\mathrm{cm} \mathrm{s}^{-1}\right)$. For these species, the "surface" contribution is equivalent to total deposition. Model results are taken from the layer closest to the measurement height ( $12.5 \mathrm{~m}$ for $\mathrm{O}_{3}, 17.8 \mathrm{~m}$ for PAN). Measurements are given as the mean $\pm 1 \sigma$.

\begin{tabular}{lcccc}
\hline Process & \multicolumn{2}{c}{ Ozone } & \multicolumn{2}{c}{ PAN } \\
\cline { 2 - 5 } & Hot & Cool & Hot & Cool \\
\hline Stomatal dep. & -0.13 & -0.23 & -0.08 & -0.14 \\
Cuticular dep. & -0.12 & -0.12 & -0.01 & -0.01 \\
Ground dep. & -0.05 & -0.05 & -0.03 & -0.03 \\
Surface & -0.30 & -0.40 & -0.12 & -0.18 \\
Chemical & 0.02 & 0.01 & -0.10 & -0.08 \\
Surf + Chem & -0.28 & -0.39 & -0.22 & -0.26 \\
Measured & $-0.37 \pm 0.12$ & $-0.49 \pm 0.11$ & $-0.63 \pm 0.25$ & $-0.49 \pm 0.27$ \\
$\%$ Difference & -24 & -20 & -65 & -47 \\
\hline
\end{tabular}

a Calculated as $100 *($ Model - Meas $) /$ Meas, where Model $=$ Surf + Chem.

cuticular ozone deposition to Loblolly pine (Karl et al., 2005) and citrus trees (Fares et al., 2010b). If our parameterization of cuticular and ground deposition over-estimates the magnitude of these processes at BFRS, then we are likely still missing a considerable $\mathrm{O}_{3}$ sink within the forest. In the extreme case where non-stomatal deposition is ignored, CAFE underpredicts observed $\mathrm{O}_{3}$ fluxes by $65 \%$ and $53 \%$ for the hot and cool periods, respectively. Modeled fluxes are also sensitive to prescribed values for eddy diffusion coefficients (Eq. 6); however, sensitivity tests indicate that diffusion would need to be significantly faster than currently modeled to increase the $\mathrm{O}_{3}$ flux (Wolfe and Thornton, 2011).

Within the current model framework, in-canopy $\mathrm{O}_{3}+\mathrm{BVOC}$ reactions are not of sufficient magnitude to influence $\mathrm{O}_{3}$ fluxes, seemingly at odds with inferred non-depositional $\mathrm{O}_{3}$ fluxes at BFRS (Kurpius and Goldstein, 2003; Goldstein et al., 2004). In these studies, the authors note that emissions of very reactive BVOC - which can drive chemical $\mathrm{O}_{3}$ fluxes - may not be included in current emission inventories. CAFE already contains emissions of highly reactive SQT that account for some of the missing ozone reactivity inferred previously (Kurpius and Goldstein, 2003; Goldstein et al., 2004). Bringing our model results into agreement with these studies, however, would require a substantial increase in emissions of the highly reactive SQT species or other yet-unmeasured BVOC. Such missing emissions have also been postulated from observations of "missing" $\mathrm{OH}$ reactivity at a forest in northern Michigan (Di Carlo et al., 2004) and from anomalously high HCHO concentrations measured at BFRS (Choi et al., 2010). For BEARPEX-2007, CAFE reproduces the observed above-canopy $\mathrm{OH}$ reactivity during the hot period (Fig. 3), when BVOC emissions should be highest. Thus, to affect ozone fluxes, unidentified emissions must react preferentially with $\mathrm{O}_{3}$ in the canopy, similar to the SQT species $\beta$-caryophyllene and $\alpha$-humulene (Bouvier-Brown et al., 2009c). The effects of very reactive BVOC on $\mathrm{O}_{3}$ chemistry should be localized to the canopy or near-leaf airspace, consistent with the observation of markedly different terpene speciation between branch enclosure and ambient measurements (Bouvier-Brown et al., 2009a). Considerable non-stomatal ozone fluxes have been observed at several other forests (Hogg et al., 2007; Coe et al., 1995; Rondon et al., 1993), but whether such fluxes are driven by surface or gas-phase processes remains an open question. Targeted model sensitivity studies together with further in situ observations could shed additional light on such issues. Understanding the fate of $\mathrm{O}_{3}$ in the forest must continue to be a priority, as the questions raised here are directly relevant to ecosystem health, aerosol formation and $\mathrm{RO}_{\mathrm{x}}$ chemistry in this environment.

\subsection{Reactive nitrogen}

The reactive nitrogen $\left(\mathrm{NO}_{\mathrm{y}}\right)$ family encompasses a wide spectrum of atmospheric oxidized nitrogen compounds, including $\mathrm{NO}_{\mathrm{x}}$, acyl peroxy nitrates (APNs), alkyl nitrates (ANs) and nitric acid $\left(\mathrm{HNO}_{3}\right)$, among others. Primary $\mathrm{NO}_{\mathrm{x}}$ sources in the troposphere include both anthropogenic (e.g. combustion and agriculture) and natural (e.g. soil and lightning) emissions (Jaeglé et al., 2005). The higher oxides of nitrogen are formed via reactions of $\mathrm{NO}_{\mathrm{x}}$ with $\mathrm{RO}_{\mathrm{x}}$ :

$$
\begin{aligned}
& \mathrm{RC}(\mathrm{O}) \mathrm{O}_{2}+\mathrm{NO}_{2} \rightleftharpoons \mathrm{RC}(\mathrm{O}) \mathrm{O}_{2} \mathrm{NO}_{2}(\mathrm{APN}) \\
& \mathrm{RO}_{2}+\mathrm{NO} \rightarrow \mathrm{RONO}_{2}(\mathrm{AN}) \\
& \mathrm{OH}+\mathrm{NO}_{2} \rightarrow \mathrm{HNO}_{3}
\end{aligned}
$$

We restrict our analysis to these four classes since they comprise the bulk of $\mathrm{NO}_{\mathrm{y}}$ at BFRS (Day et al., 2009; Ren et al., 2010) and their formation mechanisms are reasonably - if not 
Table 7. Model-measurement comparison of $\mathrm{NO}_{\mathrm{y}}$ speciation. Model results are taken from the layer closest to the measurement height. Measurements are reported as the mean $\pm 1 \sigma$. NO was not measured during BEARPEX-2007. $\Sigma \mathrm{NO}_{\mathrm{y}}$ represents the sum of all listed $\mathrm{NO}_{\mathrm{y}}$ components.

\begin{tabular}{|c|c|c|c|c|c|}
\hline \multirow[t]{2}{*}{ Species } & \multirow[t]{2}{*}{ Height/m } & \multicolumn{2}{|c|}{ Concentrations/pptv } & \multicolumn{2}{|c|}{$\%$ of $\Sigma \mathrm{NO}_{\mathrm{y}}$} \\
\hline & & Model & Meas & Model & Meas \\
\hline \multicolumn{6}{|l|}{ Hot } \\
\hline NO & 9 & 26 & - & 2 & - \\
\hline $\mathrm{NO}_{2}$ & 9 & 142 & $139 \pm 65$ & 12 & 14 \\
\hline$\Sigma \mathrm{PN}$ & 9 & 290 & $185 \pm 104$ & 25 & 18 \\
\hline$\Sigma$ AN & 9 & 125 & $147 \pm 146$ & 11 & 14 \\
\hline $\mathrm{HNO}_{3}$ & 16.8 & 562 & $555 \pm 190$ & 49 & 54 \\
\hline$\Sigma \mathrm{NO}_{\mathrm{y}}$ & & 1144 & $1028 \pm 505$ & - & - \\
\hline \multicolumn{6}{|l|}{ Cool } \\
\hline NO & 9 & 135 & - & 9 & - \\
\hline $\mathrm{NO}_{2}$ & 9 & 385 & $368 \pm 115$ & 27 & 30 \\
\hline$\Sigma \mathrm{PN}$ & 9 & 533 & $430 \pm 99$ & 37 & 38 \\
\hline$\Sigma$ AN & 9 & 93 & $119 \pm 66$ & 7 & 10 \\
\hline $\mathrm{HNO}_{3}$ & 16.8 & 285 & $273 \pm 4$ & 20 & 22 \\
\hline$\Sigma \mathrm{NO}_{\mathrm{y}}$ & & 1431 & $1234 \pm 284$ & - & - \\
\hline
\end{tabular}

yet quantitatively - understood. Table 7 compares modeled concentrations of $\mathrm{NO}_{\mathrm{y}}$ components to observations. Overall, the model is in decent agreement with measured $\Sigma \mathrm{NO}_{\mathrm{y}}$ $\left(=\mathrm{NO}+\mathrm{NO}_{2}+\Sigma \mathrm{PN}+\Sigma \mathrm{AN}+\mathrm{HNO}_{3}\right)$ and the temperaturedependence of $\mathrm{NO}_{\mathrm{y}}$ speciation, though $\Sigma \mathrm{PN}$ (comprised primarily of APNs in the model) are slightly over-predicted and $\Sigma$ AN are slightly under-predicted. Speciation is discussed in more detail below. $\Sigma \mathrm{NO}_{\mathrm{y}}$ measured during BEARPEX2007 (1-1.3 ppbv) is about half that reported for previous years $(\sim 2.5 \mathrm{ppbv}$ ), but the relative speciation is similar (Day et al., 2009; Murphy et al., 2006). This decrease is consistent with $\sim 10 \mathrm{ppbv}$ lower average $\mathrm{O}_{3}$ concentrations during BEARPEX-2007. Advection is important for maintaining reasonable concentrations of many $\mathrm{NO}_{\mathrm{y}}$ species, particularly $\mathrm{NO}_{2}$; however, advection does not significantly affect modeled vertical fluxes.

Forest-atmosphere exchange of reactive nitrogen continues to be a significant uncertainty in assessing the influence of anthropogenic nitrogen emissions on forest productivity (Magnani et al., 2007; Thomas et al., 2010) and regional air quality (Steiner et al., 2006). Quantifying dry nitrogen deposition to forests remains a challenge for several reasons. Deposition velocities may vary by an order of magnitude for different classes of $\mathrm{NO}_{\mathrm{y}}$ (Farmer and Cohen, 2008; Turnipseed et al., 2006; Horii et al., 2006). As a result, deposition can alter the relative partitioning of remaining gas-phase $\mathrm{NO}_{\mathrm{y}}$, which in turn affects $\mathrm{NO}_{\mathrm{y}}$ chemistry and deposition downwind. Furthermore, rapid in-canopy chemical transformations can alter the net forest-atmosphere exchange of $\mathrm{NO}_{\mathrm{y}}$ species (Dorsey et al., 2004; Duyzer et al., 2004; Farmer and Cohen, 2008; Walton et al., 1997; Wolfe et al., 2009). Soil- emitted $\mathrm{NO}$, often a primary $\mathrm{NO}_{\mathrm{x}}$ source in rural and remote regions (Williams et al., 1992), is rapidly converted to $\mathrm{NO}_{2}$ by reaction with $\mathrm{O}_{3}$ and peroxy radicals in the canopy (Gao et al., 1991), with implications for measuring the fluxes of $\mathrm{NO}_{\mathrm{x}}$ components. $\mathrm{NO}_{\mathrm{x}}$ partitioning within the canopy also affects the fate of APNs, which depends in part on the $\mathrm{NO} / \mathrm{NO}_{2}$ ratio. Oxidation of BVOC can enhance or alter the pathways for production of APNs and ANs, while temperature gradients can influence the decomposition of APNs to $\mathrm{NO}_{\mathrm{x}}$, affecting fluxes of both of these components (Farmer and Cohen, 2008; Wolfe et al., 2009). In what follows, we examine the modeled vertical exchange for each class of $\mathrm{NO}_{\mathrm{y}}$ with a focus on the role chemistry plays in modifying the net abovecanopy flux.

\subsection{1 $\mathrm{NO}_{\mathrm{x}}$}

Figure 7 a displays vertical profiles of $\mathrm{NO}_{2}$ mixing ratios. $\mathrm{NO}_{2}$ is lower during the hot period, likely because of faster conversion to $\mathrm{HNO}_{3}$ and a decreased APN reservoir (Day et al., 2008). Concentrations increase near the ground due to fast conversion of soil-emitted $\mathrm{NO}$ via reactions with $\mathrm{O}_{3}$ and peroxy radicals, as well as relatively enhanced thermolysis of APNs via the reverse of Reaction (R12). The measured $\mathrm{NO}_{2}$ gradient is steeper than the model during the hot period, which may be symptomatic of a deficiency in our diffusion parameterization or of soil NO fluxes that are higher than our estimate. Gradients in the $\mathrm{NO} / \mathrm{NO}_{2}$ ratio (Fig. $7 \mathrm{~b}$ ) are driven by a balance between the soil NO emission rate, rapid establishment of the NO- $\mathrm{NO}_{2}-\mathrm{O}_{3}$ equilibrium (Reactions R9-R11), and diffusion timescales. $\mathrm{NO} / \mathrm{NO}_{2}$ is lower 

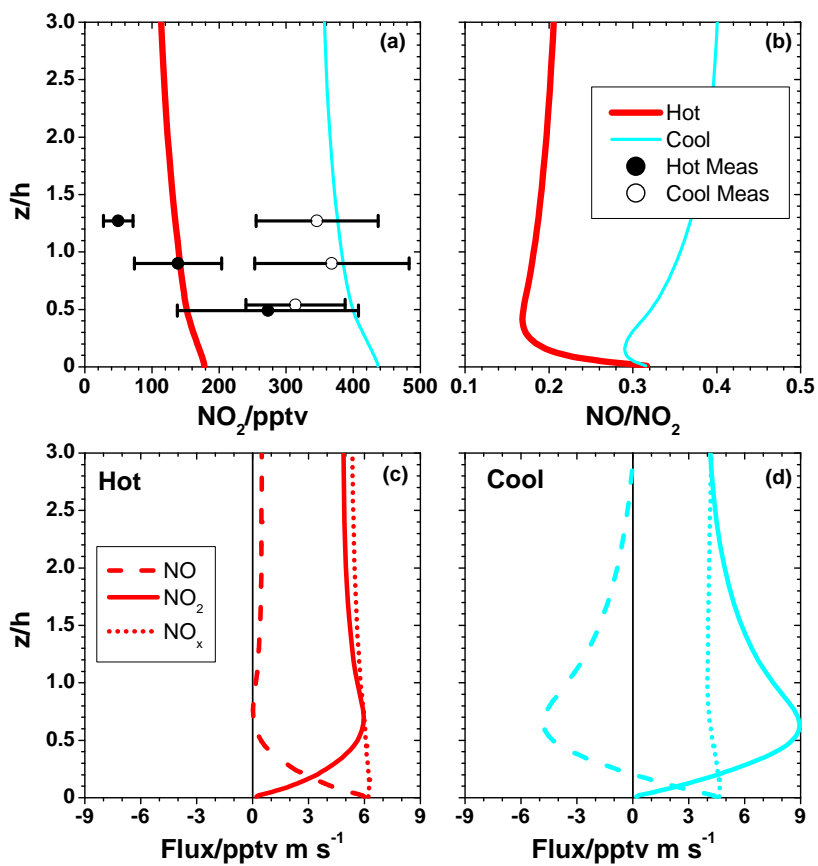

Fig. 7. (a) Vertical $\mathrm{NO}_{2}$ model profiles for the hot and cool periods. Filled and open circles represent observations (mean $\pm 1 \sigma$ ) for the hot and cool periods, respectively. The lowest cool period observation is offset on the y-axis for clarity. (b) Modeled $\mathrm{NO} / \mathrm{NO}_{2}$ ratios for the hot and cool periods. (c) Modeled flux profiles for $\mathrm{NO}, \mathrm{NO}_{2}$ and $\mathrm{NO}_{\mathrm{X}}$ for the hot period. (d) As in (c), but for the cool period.

during the hot period because of higher levels of $\mathrm{RO}_{2}$, which mainly convert $\mathrm{NO}$ to $\mathrm{NO}_{2}$ via Reaction (R3) but also to ANs via Reaction (R13).

The mirrored shape of in-canopy flux profiles (Fig. 7cd) reflects the rapid inter-conversion of $\mathrm{NO}$ and $\mathrm{NO}_{2}$. Near the ground, low radiation results in net conversion of emitted $\mathrm{NO}$ to $\mathrm{NO}_{2}$, thereby increasing fluxes of $\mathrm{NO}_{2}$ and decreasing those of NO. Flux profiles turn more vertical at $z / h \cong 0.6$, when $\mathrm{NO}_{2}$ photolysis becomes competitive with $\mathrm{NO}$ oxidation. The net $\mathrm{NO}_{\mathrm{x}}$ flux above the canopy is upward and nearly equal in magnitude to the soil $\mathrm{NO}$ emission flux, though it is mostly comprised of $\mathrm{NO}_{2}$. The canopy reduction factor, defined as the fraction of soil-emitted $\mathrm{NO}_{\mathrm{x}}$ that does not leave the canopy due to deposition and chemical transformations, is $\sim 11 \%$ for the current study. Because most of the soil-emitted $\mathrm{NO}_{\mathrm{x}}$ escapes the canopy and because the modeled $\mathrm{NO}_{\mathrm{x}}$ flux is almost entirely comprised of $\mathrm{NO}_{2}$, canopytop $\mathrm{NO}_{2}$ fluxes likely provide an indirect check on our soil NO emission flux. Unfortunately these observations were not available during BEARPEX-2007, but we may draw a rough comparison to previous studies. During the hot period, CAFE predicts an above-canopy $\mathrm{NO}_{2}$ exchange velocity of $+3.5 \mathrm{~cm} \mathrm{~s}^{-1}$, which is $50 \%$ higher than the $+2.3 \mathrm{~cm} \mathrm{~s}^{-1}$ observed by Farmer and Cohen (2008) at BFRS in August 2004. Without soil NO flux measurements from either pe- riod, we are unable to conclude whether the higher $\mathrm{NO}_{2}$ flux predicted for 2007 by CAFE is realistic.

\subsubsection{APNs}

APNs are a unique class of $\mathrm{NO}_{\mathrm{y}}$ in that their atmospheric residence time, determined partly by the chemical equilibrium (R12), is highly sensitive to temperature. Peroxyacetyl nitrate ( $\mathrm{PAN}, \mathrm{CH}_{3} \mathrm{C}(\mathrm{O}) \mathrm{O}_{2} \mathrm{NO}_{2}$ ) comprises $70-90 \%$ of the observed APN budget during BEARPEX-2007 and evolves from a variety of anthropogenic and biogenic VOC precursors. Notable minor APNs include peroxypropionyl nitrate (PPN, $\left.\mathrm{C}_{2} \mathrm{H}_{5} \mathrm{C}(\mathrm{O}) \mathrm{O}_{2} \mathrm{NO}_{2}\right)$ and peroxymethacryloyl nitrate (MPAN, $\left.\mathrm{CH}_{2} \mathrm{C}\left(\mathrm{CH}_{3}\right) \mathrm{C}(\mathrm{O}) \mathrm{O}_{2} \mathrm{NO}_{2}\right)$, which form during the oxidation of $\mathrm{C}_{2} \mathrm{H}_{5} \mathrm{CHO}$ and MACR, respectively. BEARPEX-2007 measurements (Table S1) include vertical concentration gradients and above-canopy fluxes of PAN, PPN and MPAN, as well as a separate measurement of total peroxy nitrates $(\Sigma \mathrm{PN})$ that may contain contributions from other APNs and non-acyl species such as $\mathrm{CH}_{3} \mathrm{O}_{2} \mathrm{NO}_{2}$. Most of our analysis will focus on the speciated observations, since these include fluxes.

After accounting for both thermal decomposition via the reverse reaction in (R12) and subsequent loss of the $\mathrm{RC}(\mathrm{O}) \mathrm{O}_{2}$ radical, canopy-top APN lifetimes for the current study range from $\sim 0.7 \mathrm{~h}$ during the hot period to $\sim 4.9 \mathrm{~h}$ during the cool period. Thus, both observed and modeled PAN concentrations increase by more than a factor of 2 between the hot and cool periods (Fig. 8a). PAN mixing ratios are over-predicted by $\sim 30 \%$ during the hot period but agree well with observations during the cool period. Model-measurement agreement here is partly coupled to our choice of initial/advection PAN concentrations ( $\mathrm{Ta}-$ ble 4), though an assumption of negligible background concentration seems fair given the sustained high temperatures and steadily decaying daytime PAN maxima observed during this period (Wolfe et al., 2009). This over-prediction is consistent with the steady-state analysis of LaFranchi et al. (2009), who suggested that overestimates of modeled PAN during warmer conditions may have resulted from underestimated sinks for $\mathrm{CH}_{3} \mathrm{C}(\mathrm{O}) \mathrm{O}_{2}$ (PA) radicals. Additionally, our extensive chemical mechanism predicts several individually small sources of the PA radical, neglected by LaFranchi et al. (2009), that sum to $\sim 30 \%$ of the total PA production budget. In contrast, modeled PPN and MPAN concentrations agree with observations to within 5\% for the hot period and within 17\% for the cool period (Table S2).

Roughly $15 \%$ of modeled $\Sigma$ PNs can be attributed to compounds other than PAN, PPN and MPAN during the hot period. This result is consistent with the observational inter-comparison of Wooldridge et al. (2010), who showed that APNs other than PAN, PPN, and MPAN typically make up less than $10 \%$ of $\Sigma$ PNs. It is not consistent with many other models, however, including the base MCM, which would attribute a much larger fraction of 

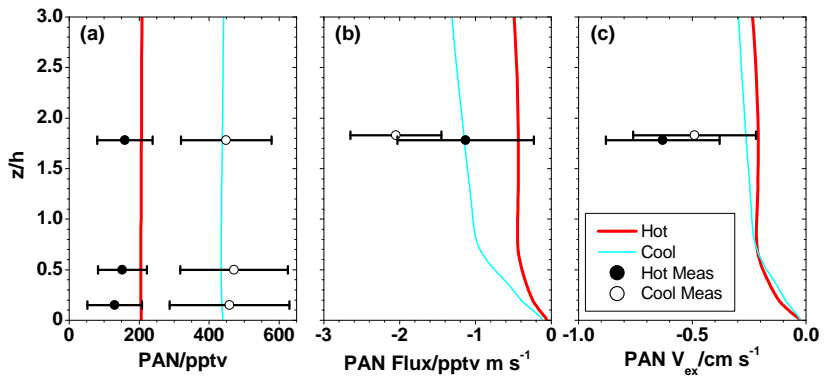

Fig. 8. Vertical profiles of (a) mixing ratios, (b) fluxes and (c) exchange velocities for PAN. Model results are shown for both hot and cool periods. Filled and open circles represent observations (mean $\pm 1 \sigma$ ) for the hot and cool periods, respectively. Observations for the cool period in (b) and (c) are offset on the y-axis for clarity.

$\Sigma$ PNs to species other than PAN, PPN, and MPAN (Perez et al., 2009). In our chemical mechanism, we neglect most anthropogenic VOC precursors (except acetaldehyde and propanal) and we invoke a rapid decomposition of $\beta$ hydroxy acyl peroxy radicals (Wolfe and Thornton, 2011). These two characteristics explain the much lower predictions of $\Sigma$ PNs other than PAN, PPN, and MPAN. For example, if we were to exclude $\beta$-hydroxy acyl peroxy decomposition, modeled concentrations of PHAN $\left(\mathrm{HOCH}_{2} \mathrm{C}(\mathrm{O}) \mathrm{O}_{2} \mathrm{NO}_{2}\right)$ and C4PAN5 $\left(\mathrm{HOC}\left(\mathrm{CH}_{3}\right)_{2} \mathrm{C}(\mathrm{O}) \mathrm{O}_{2} \mathrm{NO}_{2}\right)$, which are secondgeneration MBO oxidation products, lead to a $40 \%$ overprediction of $\Sigma$ PNs. The model overestimate of $\Sigma$ PNs during the hot period (Table 7) is mostly due the $30 \%$ overestimate of PAN.

The measured PAN gradient near the ground reveals that observations at $1.5 \mathrm{~m}$ are consistently lower than those at $5 \mathrm{~m}$, with an average difference of $26 \pm 14$ pptv (mean $\pm 1 \sigma$ ) between these two heights for the hot period. This difference constitutes a gradient of $\sim 17 \pm 9 \%$ that is not captured in the modeled PAN profile. CAFE may not adequately represent deposition to the soil and ground litter, or diffusion near the ground, where chemical sinks are largest. We explore this in more detail below.

Modeled PAN fluxes and exchange velocities (Fig. 8bc) are under-predicted by $50-60 \%$ for both periods. Within CAFE, deposition of PAN occurs primarily through stomatal uptake (Table 6). It is possible that non-stomatal deposition is under-predicted, though laboratory measurements suggest that this term should be small compared to the stomatal component (Sparks et al., 2008). The $22 \%$ decrease in the observed PAN exchange velocities between the hot and cool periods suggests a temperature-dependent in-canopy loss process that is not represented in CAFE. Surface-facilitated thermal decomposition on sunlit canopy elements (which are warmer than the surrounding air) followed by loss of the PA radical seems a feasible mechanism, though the magnitude of this process would need to be larger than our total modeled deposition rate.
Alternatively, model-measurement disagreement may be related to the interplay of gas-phase chemistry and vertical mixing. Enhanced thermal decomposition due to the strong temperature gradient at the ground (Fig. 1) forces PAN out of chemical equilibrium (i.e. $P<L$ ), resulting in net chemical loss within the canopy and increasing its downward flux. This chemical perturbation, which we will call the chemical velocity $\left(V_{\mathrm{c}}\right)$ in analogy with the deposition velocity $\left(V_{\mathrm{d}}\right)$, amounts to $-0.1 \mathrm{~cm} \mathrm{~s}^{-1}$ and $-0.08 \mathrm{~cm} \mathrm{~s}^{-1}$ for the hot and cool periods, respectively (Table 7). Wolfe et al. (2009) estimated an average chemical velocity of -0.3 and $-0.1 \mathrm{~cm} \mathrm{~s}^{-1}$ for two larger periods of BEARPEX-2007 that include our hot and cool periods. Thus, it is possible that CAFE underestimates this effect, especially during the hot period, which would also be consistent with the disagreement between near-ground modeled and measured PAN gradients as mentioned above. Decreasing diffusion in the lower canopy (as per the sensitivity test described in Sect. 3.1) does lower PAN mixing ratios by a few percent near the ground, but slower mixing ultimately leads to a decrease in the magnitude of the modeled above-cannopy PAN exchange velocity. Another potential cause for an under-estimate of the PAN chemical velocity is excess in-canopy production of PAN or more specifically its precursor, the PA radical, which could be the case if modeled $\mathrm{OH}$ mixing ratios in the lower canopy are too high (recall that we have no constraint on these below $z / h=0.9$ ). This notion emphasizes the fact that APN exchange appears to be quite sensitive to the vertical profiles in chemical production and loss.

PPN and MPAN fluxes and exchange velocities (Table 8) are mostly within the large range of observed values, except for the PPN exchange velocity during the hot period. Measured PPN exchange velocities are quite fast $\left(<-3 \mathrm{~cm} \mathrm{~s}^{-1}\right)$ during the hot period, the possible implications of which have been discussed elsewhere (Wolfe et al., 2009). Within the CAFE model framework, an exchange velocity of this magnitude can only be obtained if PPN deposition rates are increased markedly by decreasing the cuticular resistance. The high variability of PPN and MPAN exchange velocities for the chosen observation windows precludes a more detailed model evaluation for these species.

Separating APN fluxes into chemical and surface (depositional) contributions can provide a more detailed look into the factors controlling forest-atmosphere APN exchange. Figure 9 compares the chemical velocities of PAN, PPN, MPAN and C4PAN5 for the hot period, as calculated according to Eq. (9). The latter species is the primary firstgeneration APN from MBO oxidation as predicted by the MCM and is an analog of MPAN, which derives from isoprene. Even though we do not have observations for comparison, we include C4PAN5 in this analysis for demonstrative purposes. Starting near the ground, the PPN chemical velocity diverges slightly towards less negative values than PAN, while the MPAN chemical velocity is even less negative. The chemical velocity of C4PAN5 shows the largest 


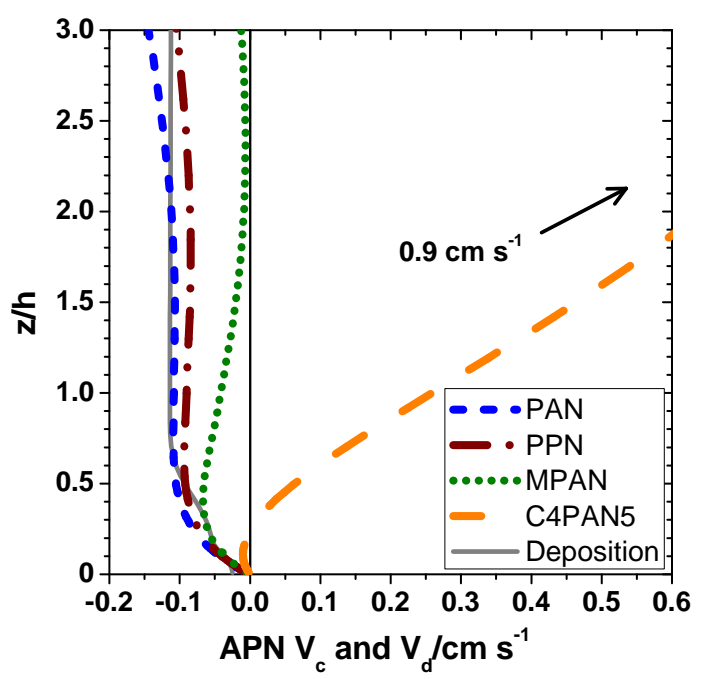

Fig. 9. Modeled chemical velocity profiles for PAN, PPN, MPAN and C4PAN5 during the hot period. The deposition velocity, which is the same for all APNs, is also shown. The chemical velocity for C4PAN5 extends off the scale $\left(0.9 \mathrm{~cm} \mathrm{~s}^{-1}\right.$ at $\left.z / h=3\right)$.

departure from PAN, becoming positive above $z / h=0.3$. These variations are not due to differences in deposition, as all APNs have the same deposition velocity in the model, which is also shown in Fig. 9. Deposition velocities may vary somewhat between APNs in reality, e.g. according to the functional groups on the carbon backbone.

The diversity of modeled APN chemical velocity profiles is largely due to varying vertical distributions of their precursors. This is particularly evident in MPAN and C4PAN5 chemical velocities. Near the ground, the chemical velocity of MPAN and C4PAN5 is still controlled by thermal losses. Within and immediately above the canopy, however, oxidation of emitted isoprene and MBO leads to formation of methacrolein (MACR) and 2-hydroxy-2methylpropionaldehyde (IBUTALOH), respectively. In our MCM-based mechanism, these aldehydes are the sole precursors of MPAN and C4PAN5, respectively, and slightly enhanced levels of these precursors will enhance MPAN and C4PAN5 formation in the canopy. This production term continues to dominate above the canopy, whereas the thermochemical loss term becomes more constant as the temperature gradient is less pronounced here (note the near-vertical gradient of the PAN chemical velocity between $z / h=1$ and 2). Production of C4PAN5 is strong enough that CAFE predicts net emission of this compound from the forest, though this prediction is sensitive to the deposition term, which may be higher than we have modeled due to the hydroxyl functionality on C4PAN5. BVOC oxidation also produces PAN precursors, but these are not as specific as those of MPAN and C4PAN5. PAN production includes significant contributions from multi-generational oxidized VOC, such as acetaldehyde and methyl glyoxal, that are not as directly linked
Table 8. Model-measurement comparison of APN exchange velocities. All measurements are from $17.8 \mathrm{~m}$ and are given as the mean $\pm 1 \sigma$. Model results are from the layer closest to the measurement height.

\begin{tabular}{lrrr}
\hline Species & Height $/ \mathrm{m}$ & \multicolumn{2}{c}{$V_{\mathrm{ex}} / \mathrm{cm} \mathrm{s}^{-1}$} \\
\cline { 3 - 4 } & & Model & Meas \\
\hline Hot & & & \\
PAN & 17.8 & -0.21 & $-0.63 \pm 0.25$ \\
PPN & 17.8 & -0.20 & $-3.3 \pm 1.0$ \\
MPAN & 17.8 & -0.13 & $-1.2 \pm 1.2$ \\
Cool & & & \\
PAN & 17.8 & -0.26 & $-0.49 \pm 0.27$ \\
PPN & 17.8 & -0.26 & $-0.2 \pm 0.54$ \\
MPAN & 17.8 & -0.15 & $0.26 \pm 0.77$ \\
\hline
\end{tabular}

to BVOC emissions and thus are more evenly distributed in the vertical.

The PPN chemical velocity is something of a special case, as the shape of its profile relative to that of PAN stems from an increased contribution from the storage term, $-\int_{0}^{z} \frac{\partial C(z)}{\partial t} d z$. In this instance, the PPN precursor propanal $\left(\mathrm{C}_{2} \mathrm{H}_{5} \mathrm{CHO}\right)$ is evenly distributed in the vertical because its sole source in CAFE is advection. PPN produced aloft is transported into the canopy but cannot escape as easily, as decreased diffusion in the canopy can serve as a "trap" for gases with weak concentration gradients. This results in a slight buildup of PPN and thus a slight positive perturbation to the flux. Chemical flux contributions are slightly dampened during the cool period (not shown), though MPAN exchange velocities are still somewhat less negative than those of PAN and PPN (Table 8).

The strength of any APN production flux will depend on a number of factors, including BVOC emission rates, $\mathrm{OH}$ mixing ratios and canopy residence times. In particular, we noted earlier (Sect. 3.1) that a substantial isoprene emission rate is required to maintain agreement with isoprene observations, though previous studies have identified advection as the primary isoprene source at BFRS (Dreyfus et al., 2002). Replacing isoprene emission with advection would reduce the MPAN production flux and bring the modeled MPAN $V_{\text {ex }}$ closer to that of PAN or PPN, because the source of MACR would no longer be elevated in the canopy. Likewise, thermochemical APN loss fluxes depend on both the absolute temperature and the shape the temperature gradient in the canopy, which may change dramatically between a young and open forest like BFRS and a more mature forest. Moreover, APN production and loss are also subject to $\mathrm{NO}_{\mathrm{x}}$ concentrations and $\mathrm{NO} / \mathrm{NO}_{2}$ ratios. To expand the relevance of these findings to other ecosystems, future modeling work should probe the sensitivity of APN fluxes to such factors, particularly temperature gradients, BVOC emissions and soil NO emissions. 
To conclude this section, we note that timescales for APN production and loss (30 min to several hours) are much longer than the modeled canopy residence time of $\sim 2 \mathrm{~min}$; however, chemistry still obviously contributes markedly to the modeled fluxes of these compounds. It is not the absolute magnitudes of production and loss, but rather sustained gradients in these terms, that can perturb mixing ratio vertical profiles and thus drive diffusive fluxes. To the extent that our model captures the average mixing process, these results suggest that comparison of reactive and mixing timescales may not be an appropriate metric by which to assess the contribution of chemistry to forest-atmosphere exchange.

\subsubsection{ANs}

Alkyl nitrates $\left(\mathrm{RONO}_{2}\right)$ are formed as minor products during $\mathrm{NO}+\mathrm{RO}_{2}$ Reaction (R13), with typical branching ratios of 5-10\% for AN formation (Atkinson and Arey, 2003). ANs are also produced during the oxidation of VOC by the nitrate radical $\left(\mathrm{NO}_{3}\right)$, though daytime $\mathrm{NO}_{3}$ concentrations are generally too low to be important for the current study. Recent work suggests that chemical mechanisms may be incomplete with regard to AN chemistry, particularly concerning their ability to "recycle" $\mathrm{NO}_{\mathrm{x}}$ during oxidation by $\mathrm{OH}$ (Rollins et al., 2009; Perring et al., 2009a, b; Horowitz et al., 2007; Paulot et al., 2009b). Deposition of ANs is also poorly constrained by observations and may depend on the functional form of the R-group. BEARPEX-2007 measurements are limited to $\Sigma A N$ concentration profiles, though earlier observations at this forest have included $\Sigma$ AN fluxes.

Figure $10 \mathrm{a}-\mathrm{c}$ displays modeled mixing ratios, fluxes and exchange velocities for $\mathrm{MBOANO}_{3}$, which is a firstgeneration oxidation product of $\mathrm{MBO}$ that comprises $\sim 50 \%$ of the modeled AN budget. Concentrations are slightly higher during the hot period, consistent with the $\Sigma \mathrm{AN}$ observations (Table 6) and with faster formation rates due to higher $\mathrm{OH}$ and BVOC concentrations. Vertical mixing ratio gradients for both periods are characteristic of strong deposition. Deposition velocities are tuned to match the value of $2.7 \mathrm{~cm} \mathrm{~s}^{-1}$ recommended by Farmer and Cohen (2008) by increasing the effective Henry's Law constant to $1 \times 10^{8} \mathrm{M} \mathrm{atm}^{-1}$, effectively lowering the cuticular resistance. The slight increase in exchange velocities between the hot and cool periods results from the $8 \%$ rise in friction velocity, leading to a decrease in the modeled laminar sublayer resistance. Deposition thus dominates the flux and exchange velocity profiles of ANs with a rate that is mostly controlled by aerodynamic transfer to canopy surfaces. A small contribution from in-canopy production shifts $\mathrm{MBOANO}_{3}$ fluxes towards less negative values by $\sim 10 \%$. Chemistry-driven fluxes could become more important if deposition rates are lower than modeled - a distinct possibility considering the limited observational constraints on this process - or if AN yields are higher. Other primary ANs derived from local BVOC (i.e. $\mathrm{MBOBNO}_{3}$ and the 4 isoprene-derived ANs, see
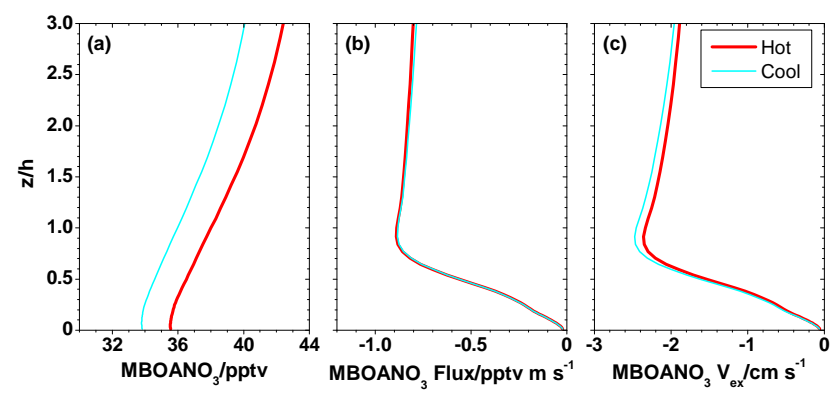

Fig. 10. Vertical profiles of (a) mixing ratios, (b) fluxes and (c) exchange velocities for $\mathrm{MBOANO}_{3}$. Model results are shown for both hot and cool periods.

Appendix A) exhibit the same vertical and seasonal patterns as $\mathrm{MBOANO}_{3}$.

\subsection{4 $\mathrm{HNO}_{3}$}

Dry deposition of gas-phase nitric acid is a primary pathway for atmosphere-to-ecosystem nitrogen transfer. $\mathrm{HNO}_{3}$ adsorbs readily to most surfaces, thus deposition is assumed to proceed at the aerodynamic limit. This view is generally supported by inferential (e.g. flux-gradient) measurements of $\mathrm{HNO}_{3}$ fluxes over forests (Horii et al., 2006; Pryor and Klemm, 2004; Sievering et al., 2001), which report deposition velocities ranging from 2 to $10 \mathrm{~cm} \mathrm{~s}^{-1}$. Previous eddy covariance measurements at BFRS (prior to BEARPEX-2007) have reported $\mathrm{HNO}_{3}$ deposition velocities of $3-4 \mathrm{~cm} \mathrm{~s}^{-1}$ during winter but have also offered evidence that fast intra-canopy chemistry can influence $\mathrm{HNO}_{3}$ fluxes, even to the point of creating a net upward flux (out of the forest) during the summer (Farmer and Cohen, 2008).

Figure 11a-c illustrate modeled profiles of $\mathrm{HNO}_{3}$ mixing ratios, fluxes and exchange velocities. $\mathrm{HNO}_{3}$ concentrations are $\sim 2$ times higher during the hot period relative to the cool period, consistent with faster production via Reaction (R14) due to higher $\mathrm{OH}$ levels. Fluxes and exchange velocities are fast and essentially driven by aerodynamically-limited deposition. As in the cases of ANs, changes in the laminar sublayer resistance give rise to different exchange velocities between the hot and cool periods. Modeled $\mathrm{HNO}_{3}$ fluxes do include a small $(\sim 5 \%)$ positive contribution due to in-canopy transformation of soil-emitted NO.

\subsubsection{Oxidized nitrogen deposition}

Ecosystem-scale nitrogen deposition affects biosphere productivity and represents a major pathway by which anthropogenic emissions influence the environment. Dry deposition typically constitutes $\sim 50 \%$ of total atmospheric $\mathrm{N}$ deposition, with the other half due to wet deposition (i.e. precipitation) (Bytnerowicz and Fenn, 1996; Sparks et al., 2008). Though $\mathrm{HNO}_{3}$ is likely the dominant dry-depositing species, 

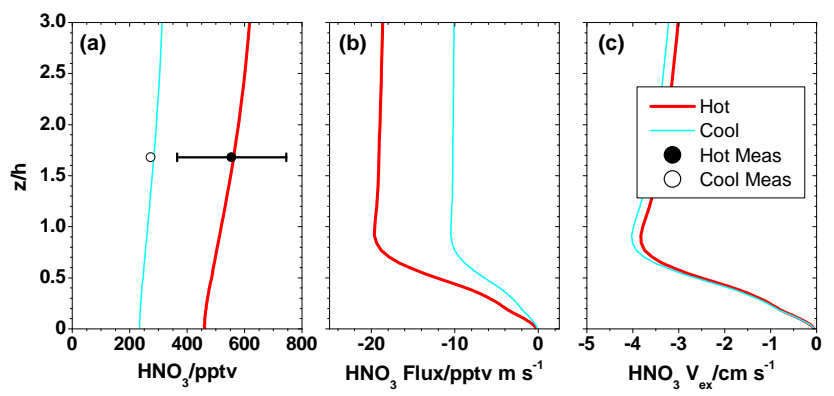

Fig. 11. Vertical profiles of (a) mixing ratios, (b) fluxes and (c) exchange velocities for $\mathrm{HNO}_{3}$. Model results are shown for both hot and cool periods. Filled and open circles represent observations (mean $\pm 1 \sigma$ ) for the hot and cool periods, respectively. The standard deviation for observed $\mathrm{HNO}_{3}$ mixing ratios in the cool period is \pm 4 pptv.

several studies have inferred that a significant fraction of the downward $\mathrm{NO}_{\mathrm{y}}$ flux is comprised of species other than nitric acid (Horii et al., 2006; Sparks et al., 2008). As detailed by the above discussion, inferring gross $\mathrm{N}$ deposition rates from net $\mathrm{NO}_{\mathrm{y}}$ fluxes without considering in-canopy chemistry can lead to errors.

Figure 12 summarizes modeled above-canopy $(z / h=2$, or $20 \mathrm{~m}) \mathrm{NO}_{\mathrm{y}}$ fluxes. Gross $\mathrm{NO}_{\mathrm{y}}$ deposition amounts to 23 and 14 pptv m s${ }^{-1}$ (11 and $7 \mathrm{ngN} \mathrm{m}^{-2} \mathrm{~s}^{-1}$ ) for the hot and cool periods, respectively. This is within the range of other estimates of $\mathrm{N}$ deposition to California forests (Bytnerowicz and Fenn, 1996; Herman et al., 2003). $\mathrm{HNO}_{3}$ constitutes $83 \%$ of deposited $\mathrm{NO}_{\mathrm{y}}$ during the hot period but only $72 \%$ during the cool period owing to decreased $\mathrm{HNO}_{3}$ and increased $\mathrm{APN}$ and $\mathrm{NO}_{2}$ mixing ratios. For both periods, upward $\mathrm{NO}_{2}$ fluxes (driven by soil $\mathrm{NO}$ emissions) decrease the net modeled $\mathrm{NO}_{\mathrm{y}}$ flux by $\sim 30 \%$ relative to the gross deposition flux. Differences between total and depositional fluxes for individual classes of $\mathrm{NO}_{\mathrm{y}}$ are consistent with our earlier discussion. For example, APN fluxes are only $60 \%$ depositional during the hot period, while total AN fluxes underestimate the depositional flux by $\sim 10 \%$. Note that our analysis is focused on gaseous oxidized nitrogen and thus does not consider dry deposition of ammonia $\left(\mathrm{NH}_{3}\right)$ or particulate ammonium nitrate $\left(\mathrm{NH}_{4} \mathrm{NO}_{3}\right)$. A small set of $\mathrm{NH}_{3}$ flux observations recorded at BFRS in 2006 suggests an average $\mathrm{NH}_{3}$ flux of $-7.4 \mathrm{ngN} \mathrm{m}^{-2} \mathrm{~s}^{-1}$ for this location (Fischer and Littlejohn, 2007). If all of this flux is depositional, $\mathrm{NH}_{3}$ uptake would be competitive with our estimated dry oxidized $\mathrm{N}$ deposition flux.

The picture presented in Fig. 12 should be interpreted with care. Relative $\mathrm{NO}_{\mathrm{y}}$ mixing ratios and deposition rates can vary widely by location and season. Deposition velocities are still highly uncertain for both APNs and ANs, largely because the mechanisms for uptake or heterogeneous loss are not understood. For example, given that CAFE underestimates PAN exchange velocities during the hot period, it is
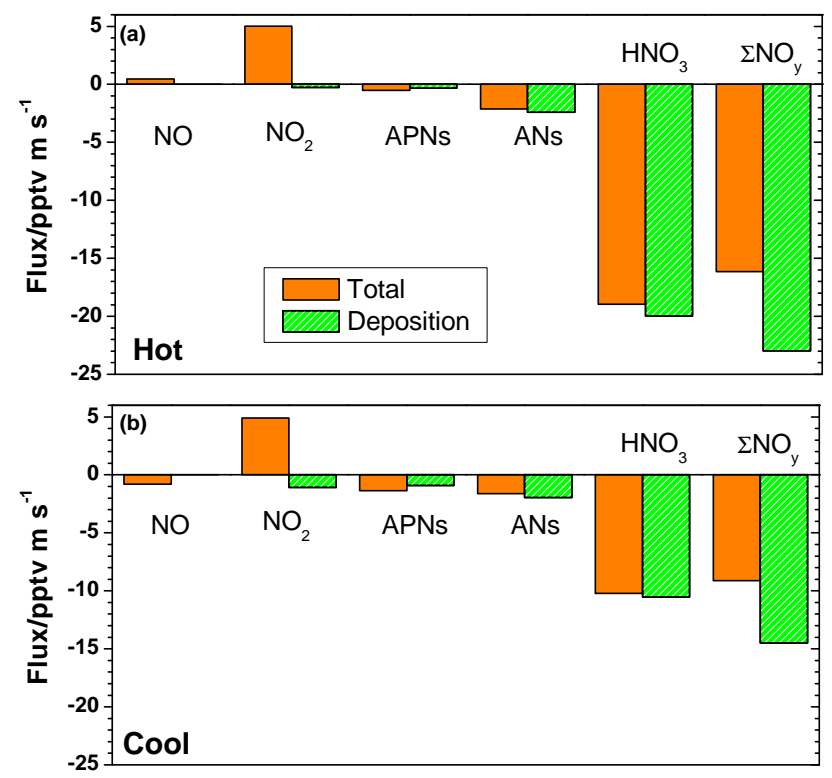

Fig. 12. Contributions of $\mathrm{NO}_{\mathrm{y}}$ components to dry depositional (green striped bars) and net (orange solid bars) fluxes as modeled at $20 \mathrm{~m}(z / h=2)$ for the (a) hot and (b) cool periods. To convert from pptv $\mathrm{m} \mathrm{s}^{-1}$ to $\mathrm{nN} \mathrm{m}^{-2} \mathrm{~s}^{-1}$, multiply by 0.46 .

possible that non-stomatal PAN deposition is faster than represented by the standard resistance parameterization. It is also likely that some deposited species may be re-emitted as $\mathrm{NO}_{2}$ or nitrous acid (HONO) rather than taken up by vegetation. In an analysis of HONO concentrations measured during BEARPEX-2007, Ren et al. (2010) require an unidentified HONO source of $1.6 \mathrm{ppbv}^{\mathrm{day}}{ }^{-1}$, or $0.02 \mathrm{pptv} \mathrm{s}^{-1}$, to reconcile observations with a steady-state estimate. Heterogeneous HONO production is generally thought to proceed via surface reactions of $\mathrm{NO}_{\mathrm{x}}$ (Goodman et al., 1999) and nitrate photolysis (Zhou et al., 2003; He et al., 2006). Assuming this missing source is purely heterogeneous (i.e. production occurs on canopy surfaces) and integrating over the canopy height, we estimate a HONO production flux of 0.2 pptv m s${ }^{-1}$, which is $\sim 67 \%$ of the modeled $\mathrm{NO}_{\mathrm{x}}$ deposition flux during the hot period. Similarly, if the total APN deposition flux during the hot period was treated as an emission of $\mathrm{NO}_{2}, \mathrm{NO}_{\mathrm{x}}$ fluxes could increase by as much as $20 \%$. Recent measurements have even suggested that $\mathrm{NO}_{\mathrm{y}}$ emitted from canopy surfaces could originate from photolysis of deposited $\mathrm{HNO}_{3}$ (Raivonen et al., 2006). Future efforts to close the $\mathrm{N}$ deposition budget should include direct field observations of speciated $\mathrm{NO}_{\mathrm{y}}$ fluxes and gradients, controlled laboratory experiments on uptake by vegetation and other surfaces (e.g. soil and ground litter), and detailed modeling work. 


\section{Conclusions}

We have used the CAFE model to simulate observations from the BEARPEX-2007 field campaign at Blodgett Forest Research Station in the Sierra Nevada, CA. Our model results highlight a number of interesting features in the extensive BEARPEX-2007 dataset.

1. CAFE under-predicts $\mathrm{OH}$ concentrations by a factor of 6 during the hot period, requiring implementation of an enhanced OH-recycling mechanism that effectively converts key organic peroxy radicals to $\mathrm{OH}$. During the cool period, model-measurement agreement for $\mathrm{HO}_{\mathrm{x}}$ is obtained without this mechanism; however, this agreement may be artificial as $\mathrm{OH}$ reactivity is underpredicted for this scenario. Thus, $\mathrm{OH}$ production is likely under-estimated by our base MCM mechanism for both periods.

2. Comparison of model results with $\mathrm{H}_{2} \mathrm{O}_{2}$ observations suggests that $\mathrm{H}_{2} \mathrm{O}_{2}$ deposition occurs at the aerodynamic limit, much faster than predicted by standard resistance parameterizations but corroborating recent direct observations.

3. Modeled $\mathrm{O}_{3}$ exchange velocities under-predict observations by $\sim 20 \%$; this discrepancy will grow if the magnitude of non-stomatal deposition is currently overestimated, as we argue. With known chemistry, incanopy chemical losses do not contribute significantly to the total modeled $\mathrm{O}_{3}$ flux. Reproducing the chemical flux inferred from previous measurements at BFRS will likely require significant increases in BVOC emissions with high reactivity towards ozone. On a larger scale, such changes carry potential ramifications for quantifying ozone-induced ecosystem stress, BVOC oxidation pathways and intra-canopy oxidant sources.

4. Nitrogen oxide $\left(\mathrm{NO}_{\mathrm{x}}=\mathrm{NO}+\mathrm{NO}_{2}\right)$ fluxes are driven by soil emissions of NO. Roughly $89 \%$ of soil-emitted $\mathrm{NO}_{\mathrm{x}}$ escapes the canopy mostly as $\mathrm{NO}_{2}$, suggesting that $\mathrm{NO}_{2}$ fluxes might be a proxy for soil $\mathrm{NO}$ emissions at this and similar young forests. Upward $\mathrm{NO}_{2}$ fluxes from soil emissions reduce the net-downward above-canopy $\mathrm{NO}_{\mathrm{y}}$ flux by $30 \%$. In other words, nitrogen deposition estimates from a total $\mathrm{NO}_{\mathrm{y}}$ flux measurement would be biased low by $30 \%$.

5. Deposition and chemical loss contribute equally to modeled PAN fluxes, but the total modeled PAN flux is $\sim 50 \%$ lower than the observations. Coupled with a $30 \%$ over-prediction of PAN mixing ratios during the hot period, this suggests that in-canopy APN sinks are either under-estimated or masked by too much production. The underlying cause of model-measurement discrepancies in APN fluxes remains unclear, partly due to uncertainties in the parameterization of vertical mixing and non-stomatal deposition. Chemical production also influences APN fluxes, especially when their formation is closely tied to the oxidation of primary BVOC emissions. In contrast, fluxes of alkyl nitrates and $\mathrm{HNO}_{3}$ are driven by deposition under our model conditions.

6. $\mathrm{HNO}_{3}$ dominates model-calculated dry $\mathrm{N}$ deposition (which excludes $\mathrm{NH}_{3}$ and particulate $\mathrm{N}$ ) during the hot period, but other classes of $\mathrm{NO}_{\mathrm{y}}$ become non-negligible $(\sim 28 \%)$ during the cool period. Such effects will carry implications for $\mathrm{N}$ deposition estimates from routine monitoring networks, which typically only measure wet and dry deposition of $\mathrm{NO}_{3}^{-} / \mathrm{NH}_{4}^{+}$and $\mathrm{HNO}_{3}$ (Sparks et al., 2008).

It is clear that significant uncertainties still limit our understanding of forest-atmosphere exchange. First, chemical mechanisms fail to reproduce observed $\mathrm{HO}_{\mathrm{x}}$ concentrations under high-BVOC conditions. A number of $\mathrm{OH}$-recycling schemes have been postulated to close this gap, but the underlying mechanisms remain unidentified, which will impede the predictive capability of any model aiming to track carbon through the emission and oxidation process. Second, Ktheory is a rough approximation to the true structure of turbulent transport within mature canopies, yet it persists as the standard for this type of model. A computationally efficient alternative to K-theory that accurately captures the key features of intra-canopy turbulence - particularly the influence of sweep-ejections and similar events - would improve confidence in future modeling efforts. Third, a lack of detailed experimental constraints on the mechanisms and efficiency of depositional processes and on BVOC emission inventories continues to prevent accurate parsing of fluxes into emission, chemistry and deposition. In particular, uncertainties in the magnitude of non-stomatal deposition for $\mathrm{O}_{3}$, APNs and other reactive species limit our ability to assess potential chemical perturbations on forest-atmosphere exchange and vice versa. In many instances, parameterizations are tuned so that observed trace gas fluxes are reproduced in models as being purely depositional or as direct emissions from the canopy to the atmosphere. This simplification will bear consequences for accurately modeling ecosystem responses to chemical and climate stresses, such as future changes in temperature and background ozone levels. Finally, our analysis of APN fluxes demonstrates that reactive timescales do not need to be faster than canopy mixing for chemistry to influence fluxes. Future efforts to interpret observed reactive trace gas fluxes must focus on both the absolute magnitudes and the gradients of production and loss that develop in a complex canopy environment. Modeling efforts should aim towards a comprehensive theory that allows incorporation of these chemical effects into surface exchange parameterizations of regional and global models, with the ultimate goal of fully representing the interaction of the forest with the atmosphere. 


\section{Appendix A}

MCM nomenclature and molecular structures

(http://mcm.leeds.ac.uk/MCM/).

\begin{tabular}{|c|c|}
\hline MCM Abbreviation & Structure \\
\hline \multicolumn{2}{|l|}{ VOC } \\
\hline MBO & $\mathrm{CH}_{2} \mathrm{CHC}\left(\mathrm{CH}_{3}\right)_{2} \mathrm{OH}$ \\
\hline C5H8 (isoprene) & $\mathrm{CH}_{2} \mathrm{C}\left(\mathrm{CH}_{3}\right) \mathrm{CHCH}_{2}$ \\
\hline MVK & $\mathrm{CH}_{2} \mathrm{CHC}(\mathrm{O}) \mathrm{CH}_{3}$ \\
\hline MACR & $\mathrm{CH}_{2} \mathrm{C}\left(\mathrm{CH}_{3}\right) \mathrm{CHO}$ \\
\hline IBUTALOH & $\mathrm{HOC}\left(\mathrm{CH}_{3}\right)_{2} \mathrm{CHO}$ \\
\hline $\mathrm{HOCH} 2 \mathrm{CHO}$ & $\mathrm{HOCH}_{2} \mathrm{CHO}$ \\
\hline MVKOH & $\mathrm{CH}_{2} \mathrm{CHC}(\mathrm{O}) \mathrm{CH}_{2} \mathrm{OH}$ \\
\hline \multicolumn{2}{|l|}{$\mathrm{ROOH}$} \\
\hline ISOPAOOH & $\mathrm{HOCH}_{2} \mathrm{C}\left(\mathrm{CH}_{3}\right) \mathrm{CHCH}_{2} \mathrm{O}_{2} \mathrm{H}$ \\
\hline ISOPBOOH & $\mathrm{CH}_{2} \mathrm{CHC}\left(\mathrm{CH}_{2} \mathrm{OH}\right)\left(\mathrm{CH}_{3}\right) \mathrm{O}_{2} \mathrm{H}$ \\
\hline ISOPCOOH & $\mathrm{HOCH}_{2} \mathrm{CHC}\left(\mathrm{CH}_{3}\right) \mathrm{CH}_{2} \mathrm{O}_{2} \mathrm{H}$ \\
\hline ISOPDOOH & $\mathrm{CH}_{2} \mathrm{C}\left(\mathrm{CH}_{3}\right) \mathrm{CH}\left(\mathrm{CH}_{2} \mathrm{OH}\right) \mathrm{O}_{2} \mathrm{H}$ \\
\hline MBOAOOH & $\mathrm{HOC}\left(\mathrm{CH}_{3}\right)_{2} \mathrm{CH}\left(\mathrm{CH}_{2} \mathrm{OH}\right) \mathrm{O}_{2} \mathrm{H}$ \\
\hline МВOBOOH & $\mathrm{HOC}\left(\mathrm{CH}_{3}\right)_{2} \mathrm{CH}(\mathrm{OH}) \mathrm{CH}_{2} \mathrm{O}_{2} \mathrm{H}$ \\
\hline ISOPBO2 & $\mathrm{CH}_{2} \mathrm{CHC}\left(\mathrm{CH}_{2} \mathrm{OH}\right)\left(\mathrm{CH}_{3}\right) \mathrm{O}_{2}$ \\
\hline
\end{tabular}

$\begin{array}{ll}\text { APNs } & \\ \text { PAN } & \mathrm{CH}_{3} \mathrm{C}(\mathrm{O}) \mathrm{O}_{2} \mathrm{NO}_{2} \\ \text { PPN } & \mathrm{CH}_{3} \mathrm{CH}_{2} \mathrm{C}(\mathrm{O}) \mathrm{O}_{2} \mathrm{NO}_{2} \\ \text { MPAN } & \mathrm{CH}_{2} \mathrm{C}\left(\mathrm{CH}_{3}\right) \mathrm{C}(\mathrm{O}) \mathrm{O}_{2} \mathrm{NO}_{2} \\ \text { PHAN } & \mathrm{HOCH}_{2} \mathrm{C}(\mathrm{O}) \mathrm{O}_{2} \mathrm{NO}_{2} \\ \text { C4PAN5 } & \left.\mathrm{HOC}_{2} \mathrm{CH}_{3}\right)_{2} \mathrm{C}(\mathrm{O}) \mathrm{O}_{2} \mathrm{NO}_{2} \\ \text { C4PAN6 } & \mathrm{CH}_{3} \mathrm{C}(\mathrm{O}) \mathrm{CH}(\mathrm{OH}) \mathrm{C}(\mathrm{O}) \mathrm{O}_{2} \mathrm{NO}_{2} \\ \text { C5PAN17 } & \mathrm{HOCH}_{2} \mathrm{CH}\left(\mathrm{CH}_{3}\right) \mathrm{CHC}(\mathrm{O}) \mathrm{O}_{2} \mathrm{NO}_{2} \\ \text { C5PAN19 } & \mathrm{HOCH}_{2} \mathrm{CHC}\left(\mathrm{CH}_{3}\right) \mathrm{C}(\mathrm{O}) \mathrm{O}_{2} \mathrm{NO}_{2} \\ & \\ \text { CH3CO3 } & \mathrm{CH}_{3} \mathrm{C}(\mathrm{O}) \mathrm{O}_{2} \\ \text { C2H5CO3 } & \mathrm{CH}_{3} \mathrm{CH} \mathrm{H}_{2} \mathrm{C}(\mathrm{O}) \mathrm{O}_{2} \\ \text { MACO3 } & \mathrm{CH}_{2} \mathrm{C}\left(\mathrm{CH}_{3}\right) \mathrm{C}(\mathrm{O}) \mathrm{O}_{2}\end{array}$

$\begin{array}{ll}\text { ANs } & \\ \text { MBOANO3 } & \mathrm{HOC}\left(\mathrm{CH}_{3}\right)_{2} \mathrm{CH}\left(\mathrm{CH}_{2} \mathrm{OH}\right) \mathrm{ONO}_{2} \\ \text { MBOBNO3 } & \mathrm{HOC}\left(\mathrm{CH}_{3}\right)_{2} \mathrm{CH}(\mathrm{OH}) \mathrm{CH}_{2} \mathrm{ONO}_{2} \\ \text { ISOPANO3 } & \mathrm{HOCH}_{2} \mathrm{C}\left(\mathrm{CH}_{3}\right) \mathrm{CHCH} \mathrm{ONO}_{2} \\ \text { ISOPBNO3 } & \mathrm{CH}_{2} \mathrm{CHC}\left(\mathrm{CH}_{2} \mathrm{OH}\right)\left(\mathrm{CH}_{3}\right) \mathrm{ONO}_{2} \\ \text { ISOPCNO3 } & \mathrm{HOCH}_{2} \mathrm{CHC}\left(\mathrm{CH} \mathrm{CH}_{2} \mathrm{CNO}_{2}\right. \\ \text { ISOPDNO3 } & \mathrm{CH}_{2} \mathrm{C}\left(\mathrm{CH}_{3}\right) \mathrm{CH}\left(\mathrm{CH}_{2} \mathrm{OH}\right) \mathrm{ONO}_{2}\end{array}$

Supplementary material related to this article is available online at: http://www.atmos-chem-phys.net/11/1269/2011/ acp-11-1269-2011-supplement.pdf.
Acknowledgements. The authors acknowledge support from a National Science Foundation grant ATM-0633897. GMW was partially supported by a U.S.-EPA STAR Fellowship Assistance under Agreement No. FP-91698901. This work has not been formally reviewed by EPA. The views expressed in this work are solely those of the authors; EPA and NSF do not endorse any products or commercial services mentioned. The authors also thank F. Paulot for helpful discussions on isoprene oxidation, S. Fares for his insights on ozone fluxes and L. Ganzeveld, T. Karl and an anonymous referee for their critical feedback on both the model and the manuscript.

Edited by: J. Lelieveld

\section{References}

Atkinson, R. and Arey, J.: Gas-phase tropospheric chemistry of biogenic volatile organic compounds: a review, Atmos. Environ., 37, S197-S219, 2003.

Baker, B., Guenther, A., Greenberg, J., Goldstein, A., and Fall, R.: Canopy fluxes of 2-methyl-3-buten-2-ol over a ponderosa pine forest by relaxed eddy accumulation: Field data and model comparison, J. Geophys. Res., 104, 26107-26114, 1999.

Bouvier-Brown, N. C., Goldstein, A. H., Gilman, J. B., Kuster, W. C., and de Gouw, J. A.: In-situ ambient quantification of monoterpenes, sesquiterpenes, and related oxygenated compounds during BEARPEX 2007: implications for gas- and particle-phase chemistry, Atmos. Chem. Phys., 9, 5505-5518, doi:10.5194/acp-9-5505-2009, 2009a.

Bouvier-Brown, N. C., Goldstein, A. H., Worton, D. R., Matross, D. M., Gilman, J. B., Kuster, W. C., Welsh-Bon, D., Warneke, C., de Gouw, J. A., Cahill, T. M., and Holzinger, R.: Methyl chavicol: characterization of its biogenic emission rate, abundance, and oxidation products in the atmosphere, Atmos. Chem. Phys., 9, 2061-2074, doi:10.5194/acp-9-2061-2009, 2009b.

Bouvier-Brown, N. C., Holzinger, R., Palitzsch, K., and Goldstein, A. H.: Large emissions of sesquiterpenes and methyl chavicol quantified from branch enclosure measurements, Atmos. Environ., 43, 389-401, 2009c.

Brune, W. H., van Duin, D., Mao, J., and Ren, X.: $\mathrm{OH}$ and $\mathrm{HO}_{2}$ Measurement in Blodgett Forest, CA during BEARPEX 2009, 2010 AGU Fall Meeting, San Francisco, CA, Abstract A51G-02, 2010.

Bytnerowicz, A. and Fenn, M. E.: Nitrogen deposition in California forests: a review, Environ. Pollut., 92, 127-146, 1996.

Cantrell, C. A., Lind, J. A., Shetter, R. E., Calvert, J. G., Goldan, P. D., Kuster, W., Fehsenfeld, F. C., Montzka, S. A., Parrish, D. D., Williams, E. J., Buhr, M. P., Westberg, H. H., Allwine, G., and Martin, R.: Peroxy-Radicals In The Rose Experiment Measurement And Theory, J. Geophys. Res.-Atmos., 97, 2067120686, 1992.

Choi, W., Faloona, I. C., Bouvier-Brown, N. C., McKay, M., Goldstein, A. H., Mao, J., Brune, W. H., LaFranchi, B. W., Cohen, R. C., Wolfe, G. M., Thornton, J. A., Sonnenfroh, D. M., and Millet, D. B.: Observations of elevated formaldehyde over a forest canopy suggest missing sources from rapid oxidation of arboreal hydrocarbons, Atmos. Chem. Phys., 10, 8761-8781, doi:10.5194/acp-10-8761-2010, 2010. 
Ciccioli, P., Brancaleoni, E., Frattoni, M., Di Palo, V., Valentini, R., Tirone, G., Seufert, G., Bertin, N., Hansen, U., Csiky, O., Lenz, R., and Sharma, M.: Emission of reactive terpene compounds from orange orchards and their removal by within-canopy processes, J. Geophys. Res.-Atmos., 104, 8077-8094, 1999.

Coe, H., Gallagher, M. W., Choularton, T. W., and Dore, C.: Canopy Scale Measurements Of Stomatal And Cuticular O-3 Uptake By Sitka Spruce, Atmos. Environ., 29, 1413-1423, 1995.

Da Silva, G., Graham, C., and Wang, Z. F.: Unimolecular betaHydroxyperoxy Radical Decomposition with $\mathrm{OH}$ Recycling in the Photochemical Oxidation of Isoprene, Environ. Sci. Technol., 44, 250-256, 2010.

Darrall, N. M.: The Effect Of Air-Pollutants On Physiological Processes In Plants, Plant Cell Environ., 12, 1-30, 1989.

Day, D. A., Wooldridge, P. J., and Cohen, R. C.: Observations of the effects of temperature on atmospheric $\mathrm{HNO}_{3}, \Sigma$ ANs, $\Sigma$ PNs, and $\mathrm{NO}_{\mathrm{X}}$ : evidence for a temperature-dependent $\mathrm{HO}_{\mathrm{X}}$ source, Atmos. Chem. Phys., 8, 1867-1879, doi:10.5194/acp-8-1867-2008, 2008.

Day, D. A., Farmer, D. K., Goldstein, A. H., Wooldridge, P. J., Minejima, C., and Cohen, R. C.: Observations of $\mathrm{NO}_{\mathrm{x}}, \Sigma \mathrm{PNs}$, $\Sigma \mathrm{ANs}$, and $\mathrm{HNO}_{3}$ at a Rural Site in the California Sierra Nevada Mountains: summertime diurnal cycles, Atmos. Chem. Phys., 9, 4879-4896, doi:10.5194/acp-9-4879-2009, 2009.

Di Carlo, P., Brune, W. H., Martinez, M., Harder, H., Lesher, R., Ren, X. R., Thornberry, T., Carroll, M. A., Young, V., Shepson, P. B., Riemer, D., Apel, E., and Campbell, C.: Missing OH reactivity in a forest: Evidence for unknown reactive biogenic VOCs, Science, 304, 722-725, 2004.

Dillon, M. B., Lamanna, M. S., Schade, G. W., Goldstein, A., and Cohen, R. C.: Chemical evolution of the Sacramento urban plume: Transport and oxidation, J. Geophys. Res., 107, 4045, doi:10.1029/2001JD000969, 2002.

Dorsey, J. R., Duyzer, J. H., Gallagher, M. W., Coe, H., Pilegaard, K., Weststrate, J. H., Jensen, N. O., and Walton, S.: Oxidized nitrogen and ozone interaction with forests. I: Experimental observations and analysis of exchange with Douglas fir, Q. J. Roy. Meteorol. Soc., 130, 1941-1955, 2004.

Dreyfus, G. B., Schade, G. W., and Goldstein, A. H.: Observational constraints on the contribution of isoprene oxidation to ozone production on the western slope of the Sierra Nevada, California, J. Geophys. Res.-Atmos., 107, 4365-4382, doi:10.1029/2001JD001490, 2002.

Duyzer, J. H., Dorsey, J. R., Gallagher, M. W., Pilegaard, K., and Walton, S.: Oxidized nitrogen and ozone interaction with forests. II: Multi-layer process-oriented modelling results and a sensitivity study for Douglas fir, Q. J. Roy. Meteorol. Soc., 130, 19571971, 2004.

Erisman, J. W., Draaijers, G. P. J., Steingrover, E., Van Dijk, H., Boxman, A., and de Vries, W.: Assessment of the exposure and loads of acidifying and eutrophying pollutants and ozone, as well as their, harmful influence on the vitality of the trees and the Speulder forest ecosystem as a whole, Water Air Soil Pollut., 105, 539-571, 1998.

Faloona, I., Tan, D., Brune, W., Hurst, J., Barket, D., Couch, T. L., Shepson, P., Apel, E., Riemer, D., Thornberry, T., Carroll, M. A., Sillman, S., Keeler, G. J., Sagady, J., Hooper, D., and Paterson, K.: Nighttime observations of anomalously high levels of hydroxyl radicals above a deciduous forest canopy, J. Geophys.
Res.-Atmos., 106, 24315-24333, 2001.

Fares, S., McKay, M., Holzinger, R., and Goldstein, A. H.: Ozone fluxes in a Pinus ponderosa ecosystem are dominated by nonstomatal processes: Evidence from long-term continuous measurements, Agr. Forest Meteorol., 150, 420-431, 2010a.

Fares, S., Park, J. H., Ormeno, E., Gentner, D. R., McKay, M., Loreto, F., Karlik, J., and Goldstein, A. H.: Ozone uptake by citrus trees exposed to a range of ozone concentrations, Atmos. Environ., 44, 3404-3412, 2010 b.

Farmer, D. K. and Cohen, R. C.: Observations of $\mathrm{HNO}_{3}, \Sigma \mathrm{AN}$, $\Sigma \mathrm{PN}$ and $\mathrm{NO}_{2}$ fluxes: evidence for rapid $\mathrm{HO}_{\mathrm{x}}$ chemistry within a pine forest canopy, Atmos. Chem. Phys., 8, 3899-3917, doi:10.5194/acp-8-3899-2008, 2008.

Fischer, M. L. and Littlejohn, D.: Ammonia at Blodgett Forest, Sierra Nevada, USA, Atmos. Chem. Phys. Discuss., 7, 1413914169, doi:10.5194/acpd-7-14139-2007, 2007.

Forkel, R., Klemm, O., Graus, M., Rappengluck, B., Stockwell, W. R., Grabmer, W., Held, A., Hansel, A., and Steinbrecher, R.: Trace gas exchange and gas phase chemistry in a Norway spruce forest: A study with a coupled 1-dimensional canopy atmospheric chemistry emission model, Atmos. Environ., 40, S28S42, 2006.

Fowler, D., Pilegaard, K., Sutton, M. A., Ambus, P., Raivonen, M., Duyzer, J., Simpson, D., Fagerli, H., Fuzzi, S., Schjoerring, J. K., Granier, C., Neftel, A., Isaksen, I. S. A., Laj, P., Maione, M., Monks, P. S., Burkhardt, J., Daemmgen, U., Neirynck, J., Personne, E., Wichink-Kruit, R., Butterbach-Bahl, K., Flechard, C., Tuovinen, J. P., Coyle, M., Gerosa, G., Loubet, B., Altimir, N., Gruenhage, L., Ammann, C., Cieslik, S., Paoletti, E., Mikkelsen, T. N., Ro-Poulsen, H., Cellier, P., Cape, J. N., Horvath, L., Loreto, F., Niinemets, U., Palmer, P. I., Rinne, J., Misztal, P., Nemitz, E., Nilsson, D., Pryor, S., Gallagher, M. W., Vesala, T., Skiba, U., Brueggemann, N., Zechmeister-Boltenstern, S., Williams, J., O’Dowd, C., Facchini, M. C., de Leeuw, G., Flossman, A., Chaumerliac, N., and Erisman, J. W.: Atmospheric composition change: Ecosystems-Atmosphere interactions, Atmos. Environ., 43, 5193-5267, 2009.

Ganzeveld, L. N., Lelieveld, J., Dentener, F. J., Krol, M. C., Bouwman, A. J., and Roelofs, G. J.: Global soil-biogenic NOx emissions and the role of canopy processes, J. Geophys. Res.-Atmos., 107(D16), 4298, doi:10.1029/2001JD001289, 2002a.

Ganzeveld, L. N., Lelieveld, J., Dentener, F. J., Krol, M. C., and Roelofs, G.-J.: Atmosphere-biosphere trace gas exchanges simulated with a single-column model, J. Geophys. Res., 107, 4297 4318, doi:10.1029/2001JD000684, 2002b.

Ganzeveld, L., Valverde-Canossa, J., Moortgat, G. K., and Steinbrecher, R.: Evaluation of peroxide exchanges over a coniferous forest un a single-column chemistry-climate model, Atmos. Environ., 40, S68-S80, doi:10.1016/j.atmosenv.2006.01.062, 2006.

Gao, W., Wesely, M. L., and Lee, I. Y.: A numerical study of the effects of air chemistry on fluxes of $\mathrm{NO}, \mathrm{NO}_{2}$, and $\mathrm{O}_{3}$ near the surface, J. Geophys. Res., 96, 18761-18769, 1991.

Gao, W., Wesely, M. L., and Doskey, P. V.: Numerical modeling of the turbulent diffusion and chemistry of $\mathrm{NO}_{\mathrm{x}}, \mathrm{O}_{3}$, isoprene, and other reactive trace gases in and above a forest canopy, J. Geophys. Res., 98, 18339-18353, 1993.

Goldstein, A. H., Hultman, N. E., Fracheboud, J. M., Bauer, M. R., Panek, J. A., Xu, M., Qi, Y., Guenther, A. B., and Baugh, W.: Effects of climate variability on the carbon dioxide, water, 
and sensible heat fluxes above a ponderosa pine plantation in the Sierra Nevada (CA), Agr. Forest Meteorol., 101, 113-129, 2000.

Goldstein, A. H., Schade, G. W., and Dreyfus, G.: Whole Ecosystem Measurements of Biogenic Hydrocarbon Emissions, Final Report, State of California Air Resources Board Award No. 98328, 2001.

Goldstein, A. H., McKay, M., Kurpius, M. R., Schade, G. W., Lee, A., Holzinger, R., and Rasmussen, R. A.: Forest thinning experiment confirms ozone deposition to forest canopy is dominated by reaction with biogenic VOCs, Geophys. Res. Lett., 31, L22106, doi:10.1029/2004GL021259, 2004.

Goldstein, A. H., Koven, C. D., Heald, C. L., and Fung, I. Y.: Biogenic carbon and anthropogenic pollutants combine to form a cooling haze over the southeastern United States, P. Natl. Acad. Sci. USA, 106, 8835-8840, 2009.

Goodman, A. L., Underwood, G. M., and Grassian, V. H.: Heterogeneous reaction of NO2: Characterization of gas-phase and adsorbed products from the reaction, $2 \mathrm{NO}(2)(\mathrm{g})+\mathrm{H} 2 \mathrm{O}(\mathrm{a})->$ $\mathrm{HONO}(\mathrm{g})+\mathrm{HNO} 3(\mathrm{a})$ on hydrated silica particles, J. Phys. Chem. A, 103, 7217-7223, 1999.

Gray, D. W., Lerdau, M. T., and Goldstein, A. H.: Influences of temperature history, water stress, and needle age on methylbutenol emissions, Ecology, 84, 765-776, 2003.

Gray, D. W., Goldstein, A. H., and Lerdau, M. T.: Thermal history regulates methylbutenol basal emission rate in Pinus ponderosa, Plant Cell Environ., 29, 1298-1308, 2006.

Guenther, A., Hewitt, C. N., Erickson, D., Fall, R., Geron, C., Graedel, T., Harley, P., Klinger, L., Lerdau, M. T., McKay, W. A., Pierce, T., Scholes, B., Steinbrecher, R., Tallamraju, R., Taylor, J., and Zimmerman, P.: A global model of natural volatile organic compound emissions, J. Geophys. Res., 100, 8873-8892, 1995.

Hall, B. D. and Claiborn, C. S.: Measurements of the dry deposition of peroxides to a Canadian boreal forest, J. Geophys. Res.Atmos., 102, 29343-29353, 1997.

Harley, P., Fridd-Stroud, V., Greenberg, J., Guenther, A., and Vasconcellos, P.: Emission of 2-methyl-3-buten-2-ol by pines: A potentially large natural source of reactive carbon to the atmosphere, J. Geophys. Res., 103, 25479-25486, 1998.

He, Y., Zhou, X. L., Hou, J., Gao, H. L., and Bertman, S. B.: Importance of dew in controlling the air-surface exchange of HONO in rural forested environments, Geophys. Res. Lett., 33, L02813, doi:10.1029/2005GL024348, 2006.

Herman, D. J., Halverson, L. J., and Firestone, M. K.: Nitrogen Dynamics in an Annual Grassland: Oak Canopy, Climate, and Microbial Population Effects, Ecological Applications, 13, 593604, 2003.

Hofzumahaus, A., Rohrer, F., Lu, K., Bohn, B., Brauers, T., Chang, C.-C., Fuchs, H., Holland, F., Kita, K., Kondo, Y., Li, X., Lou, S., Shao, M., Zeng, L., Wahner, A., and Zhang, Y.: Amplified Trace Gas Removal in the Troposphere, Science, 324, 17021704, doi:10.1126/science.1164566, 2009.

Hogg, A., Uddling, J., Ellsworth, D., Carroll, M. A., Pressley, S., Lamb, B., and Vogel, C.: Stomatal and non-stomatal fluxes of ozone to a northern mixed hardwood forest, Tellus B, 59, 514$525,2007$.

Holzinger, R., Lee, A., Paw, K. T., and Goldstein, U. A. H.: Observations of oxidation products above a forest imply biogenic emissions of very reactive compounds, Atmos. Chem. Phys., 5,
67-75, doi:10.5194/acp-5-67-2005, 2005.

Horii, C. V., Munger, J. W., Wofsy, S. C., Zahniser, M., Nelson, D., and McManus, J. B.: Atmospheric reactive nitrogen concentration and flux budgets at a Northeastern U.S. forest site, Agr. Forest Meteorol., 136, 159-174, 2006.

Horowitz, L. W., Fiore, A. M., Milly, G. P., Cohen, R. C., Perring, A., Wooldridge, P. J., Hess, P. G., Emmons, L. K., and Lamarque, J. F.: Observational constraints on the chemistry of isoprene nitrates over the eastern United States, J. Geophys. Res.-Atmos., 112, D12S08, doi:10.1029/2006JD007747, 2007.

Isaksen, I. S. A., Granier, C., Myhre, G., Berntsen, T. K., Dalsoren, S. B., Gauss, M., Klimont, Z., Benestad, R., Bousquet, P., Collins, W., Cox, T., Eyring, V., Fowler, D., Fuzzi, S., Jockel, P., Laj, P., Lohmann, U., Maione, M., Monks, P., Prevot, A. S. H., Raes, F., Richter, A., Rognerud, B., Schulz, M., Shindell, D., Stevenson, D. S., Storelvmo, T., Wang, W. C., van Weele, M., Wild, M., and Wuebbles, D.: Atmospheric composition change: Climate-Chemistry interactions, Atmos. Environ., 43, 5138-5192, 2009.

Jacobson, M. Z.: Fundamentals of Atmospheric Modeling, Cambridge University Press, New York, 2005.

Jaeglé, L., Steinberger, L., Martin, R. V., and Chance, K.: Global partitioning of $\mathrm{NO}_{\mathrm{x}}$ sources using satellite observations: Relative roles of fossil fuel combustion, biomass burning and soil emissions, Faraday Discuss., 130, 407-423, doi:10.1039/b502128f, 2005.

Karl, T., Harley, P., Guenther, A., Rasmussen, R., Baker, B., Jardine, K., and Nemitz, E.: The bi-directional exchange of oxygenated VOCs between a loblolly pine (Pinus taeda) plantation and the atmosphere, Atmos. Chem. Phys., 5, 3015-3031, doi:10.5194/acp-5-3015-2005, 2005.

Karl, T., Harley, P., Emmons, L., Thornton, B., Guenther, A., Basu, C., Turnipseed, A., and Jardine, K.: Efficient Atmospheric Cleansing of Oxidized Organic Trace Gases by Vegetation, Science, 330, 816-819, 2010.

Kurpius, M. R. and Goldstein, A. H.: Gas-phase chemistry dominates $\mathrm{O}_{3}$ loss to a forest, implying a source of aerosols and hydroxyl radicals to the atmosphere, Geophys. Res. Lett., 30, 13711374, doi:10.1029/2002GL016785, 2003.

LaFranchi, B. W., Wolfe, G. M., Thornton, J. A., Harrold, S. A., Browne, E. C., Min, K. E., Wooldridge, P. J., Gilman, J. B., Kuster, W. C., Goldan, P. D., de Gouw, J. A., McKay, M., Goldstein, A. H., Ren, X., Mao, J., and Cohen, R. C.: Closing the peroxy acetyl nitrate budget: observations of acyl peroxy nitrates (PAN, PPN, and MPAN) during BEARPEX 2007, Atmos. Chem. Phys., 9, 7623-7641, doi:10.5194/acp-9-7623-2009, 2009.

Lee, A., Goldstein, A. H., Keywood, M. D., Gao, S., Varutbangkul, V., Bahreini, R., Ng, N. L., Flagan, R. C., and Seinfeld, J. H.: Gas-phase products and secondary aerosol yields from the ozonolysis of ten different terpenes, J. Geophys. Res., 111, 118, doi:10.1029/2005JD006437, 2006a.

Lee, A., Goldstein, A. H., Kroll, J. H., Ng, N. L., Varutbangkul, V., Flagan, R. C., and Seinfeld, J. H.: Gas-phase products and secondary aerosol yields from the photooxidation of 16 different terpenes, J. Geophys. Res., 111, 1-25, doi:10.1029/2006JD007050, 2006b.

Lelieveld, J., Butler, T. M., Crowley, J. N., Dillon, T. J., Fischer, H., Ganzeveld, L., Harder, H., Lawrence, M. G., Martinez, M., Taraborrelli, D., and Williams, J.: Atmospheric oxidation 
capacity sustained by a tropical forest, Nature, 452, 737-740, doi:10.1038/nature06870, 2008.

Li, Y. J., Chen, Q., Guzman, M. I., Chan, C. K., and Martin, S. T.: Second-generation products contribute substantially to the particle-phase organic material produced by $\beta$-caryophyllene ozonolysis, Atmos. Chem. Phys., 11, 121-132, doi:10.5194/acp11-121-2011, 2011.

Magnani, F., Mencuccini, M., Borghetti, M., Berbigier, P., Berninger, F., Delzon, S., Grelle, A., Hari, P., Jarvis, P. G., Kolari, P., Kowalski, A. S., Lankreijer, H., Law, B. E., Lindroth, A., Loustau, D., Manca, G., Moncrieff, J. B., Rayment, M., Tedeschi, V., Valentini, R., and Grace, J.: The human footprint in the carbon cycle of temperate and boreal forests, Nature, 447, 849-851, 2007.

Makar, P. A., Fuentes, J. D., Wang, D., Staebler, R. M., and Wiebe, H. A.: Chemical processing of biogenic hydrocarbons within and above a temperate deciduous forest, J. Geophys. Res., 104, 3581-3603, 1999.

Mao, J., Ren, X., Chen, Z., Brune, W., LaFranchi, B., Cohen, R., Gilman, J., and deGouw, $\mathrm{J}_{\text {.: }} \mathrm{HO}_{\mathrm{x}}$ chemistry in and above a forest canopy in seasonal transition, AGU Fall Meeting, Abstract A32C-03, 2008.

Mao, J., Ren, X., Brune, W. H., Olson, J. R., Crawford, J. H., Fried, A., Huey, L. G., Cohen, R. C., Heikes, B., Singh, H. B., Blake, D. R., Sachse, G. W., Diskin, G. S., Hall, S. R., and Shetter, R. E.: Airborne measurement of $\mathrm{OH}$ reactivity during INTEX-B, Atmos. Chem. Phys., 9, 163-173, doi:10.5194/acp-9-163-2009, 2009.

Martinez, M., Harder, H., Kovacs, T. A., Simpas, J. B., Bassis, J., Lesher, R., Brune, W. H., Frost, G. J., Williams, E. J., Stroud, C. A., Jobson, B. T., Roberts, J. M., Hall, S. R., Shetter, R. E., Wert, B., Fried, A., Alicke, B., Stutz, J., Young, V. L., White, A. B., and Zamora, R. J.: $\mathrm{OH}$ and $\mathrm{HO} 2$ concentrations, sources, and loss rates during the Southern Oxidants Study in Nashville, Tennessee, summer 1999, J. Geophys. Res.-Atmos., 108, D194617, doi:10.1029/2003JD003551, 2003.

Murphy, J. G., Day, D. A., Cleary, P. A., Wooldridge, P. J., and Cohen, R. C.: Observations of the diurnal and seasonal trends in nitrogen oxides in the western Sierra Nevada, Atmos. Chem. Phys., 6, 5321-5338, doi:10.5194/acp-6-5321-2006, 2006.

Paulot, F., Beaver, M. R., St. Clair, J., Spencer, K. M., Crounse, J., and Wennberg, P. O.: Exchange of hydrogen peroxide and nitric acid over a ponerosa forest measured by eddy covariance, AGU Fall Meeting, San Francisco, CA, Abstract A41D-0133, 2009a.

Paulot, F., Crounse, J. D., Kjaergaard, H. G., Kroll, J. H., Seinfeld, J. H., and Wennberg, P. O.: Isoprene photooxidation: new insights into the production of acids and organic nitrates, Atmos. Chem. Phys., 9, 1479-1501, doi:10.5194/acp-9-1479-2009, 2009b.

Paulot, F., Crounse, J. D., Kjaergaard, H. G., Kurten, A., St Clair, J. M., Seinfeld, J. H., and Wennberg, P. O.: Unexpected Epoxide Formation in the Gas-Phase Photooxidation of Isoprene, Science, 325, 730-733, 2009c.

Paulson, S. E., Chung, M., Sen, A. D., and Orzechowska, G.: Measurement of $\mathrm{OH}$ radical formation from the reaction of ozone with several biogenic alkenes, J. Geophys. Res.-Atmos., 103, 25533-25539, 1998.

Peeters, J., Nguyen, T. L., and Vereecken, L.: $\mathrm{HO}_{\mathrm{x}}$ radical regeneration in the oxidation of isoprene, Phys. Chem. Chem. Phys., 11,
5935-5939, 2009.

Pérez, I. M., LaFranchi, B. W., and Cohen, R. C.: Nitrogen oxide chemistry in an urban plume: investigation of the chemistry of peroxy and multifunctional organic nitrates with a Lagrangian model, Atmos. Chem. Phys. Discuss., 9, 27099-27165, doi:10.5194/acpd-9-27099-2009, 2009.

Perring, A. E., Bertram, T. H., Wooldridge, P. J., Fried, A., Heikes, B. G., Dibb, J., Crounse, J. D., Wennberg, P. O., Blake, N. J., Blake, D. R., Brune, W. H., Singh, H. B., and Cohen, R. C.: Airborne observations of total RONO2: new constraints on the yield and lifetime of isoprene nitrates, Atmos. Chem. Phys., 9, 1451-1463, doi:10.5194/acp-9-1451-2009, 2009a.

Perring, A. E., Wisthaler, A., Graus, M., Wooldridge, P. J., Lockwood, A. L., Mielke, L. H., Shepson, P. B., Hansel, A., and Cohen, R. C.: A product study of the isoprene $+\mathrm{NO}_{3}$ reaction, Atmos. Chem. Phys., 9, 4945-4956, doi:10.5194/acp-9-4945-2009, 2009b.

Pryor, S. C. and Klemm, O.: Experimentally derived estimates of nitric acid dry deposition velocity and viscous sub-layer resistance at a conifer forest, Atmos. Environ., 38, 2769-2777, 2004.

Qi, B., Takami, A., and Hatakeyama, S.: Peroxy radical concentrations measured at a forest canopy in Nikko, Japan, in summer 2002, J. Atmos. Chem., 52, 63-79, 2005.

Raivonen, M., Bonn, B., Sanz, M. J., Vesala, T., Kulmala, M., and Hari, P.: UV-induced NOy emissions from Scots pine: Could they originate from photolysis of deposited $\mathrm{HNO}_{3}$ ?, Atmos. Environ., 40, 6201-6213, 2006.

Raupach, M. R.: A practical Lagrangian method for relating scalar concentrations to source distributions in vegetation canopies, Q. J. Roy. Meteorol. Soc., 115, 609-632, 1989.

Ren, X. R., Olson, J. R., Crawford, J. H., Brune, W. H., Mao, J. Q., Long, R. B., Chen, Z., Chen, G., Avery, M. A., Sachse, G. W., Barrick, J. D., Diskin, G. S., Huey, L. G., Fried, A., Cohen, R. C., Heikes, B., Wennberg, P. O., Singh, H. B., Blake, D. R., and Shetter, R. E.: $\mathrm{HO}_{\mathrm{x}}$ chemistry during INTEX-A 2004: Observation, model calculation, and comparison with previous studies, J. Geophys. Res.-Atmos., 113, D05310, doi:10.1029/2003JD003551, 2008.

Ren, X., Gao, H., Zhou, X., Crounse, J. D., Wennberg, P. O., Browne, E. C., LaFranchi, B. W., Cohen, R. C., McKay, M., Goldstein, A. H., and Mao, J.: Measurement of atmospheric nitrous acid at Bodgett Forest during BEARPEX2007, Atmos. Chem. Phys., 10, 6283-6294, doi:10.5194/acp-10-6283-2010, 2010.

Rollins, A. W., Kiendler-Scharr, A., Fry, J. L., Brauers, T., Brown, S. S., Dorn, H.-P., Dubé, W. P., Fuchs, H., Mensah, A., Mentel, T. F., Rohrer, F., Tillmann, R., Wegener, R., Wooldridge, P. J., and Cohen, R. C.: Isoprene oxidation by nitrate radical: alkyl nitrate and secondary organic aerosol yields, Atmos. Chem. Phys., 9, 6685-6703, doi:10.5194/acp-9-6685-2009, 2009.

Rondon, A., Johansson, C., and Granat, L.: Dry Deposition Of Nitrogen-Dioxide And Ozone To Coniferous Forests, J. Geophys. Res.-Atmos., 98, 5159-5172, 1993.

Rummel, U., Ammann, C., Kirkman, G. A., Moura, M. A. L., Foken, T., Andreae, M. O., and Meixner, F. X.: Seasonal variation of ozone deposition to a tropical rain forest in southwest Amazonia, Atmos. Chem. Phys., 7, 5415-5435, doi:10.5194/acp-75415-2007, 2007.

Schade, G. W. and Goldstein, A. H.: Plant physiological influences 
on the fluxes of oxygenated volatile organic compounds from ponderosa pine trees, J. Geophys. Res.-Atmos., 107, 4082-4091, 2002.

Schade, G. W., Goldstein, A. H., Gray, D. W., and Lerdau, M. T.: Canopy and leaf level 2-methyl-3-buten-2-ol fluxes from a ponderosa pine plantation, Atmos. Environ., 34, 3535-3544, 2000.

Seinfeld, J. H. and Pandis, S. N.: Atmospheric Chemistry and Physics, 2nd ed., John Wiley and Sons, Inc., Hoboken, NJ, 2006.

Sievering, H., Kelly, T., McConville, G., Seibold, C., and Turnipseed, A.: Nitric acid dry deposition to conifer forests: Niwot Ridge spruce-fir-pine study, Atmos. Environ., 35, 38513859, 2001.

Sitch, S., Cox, P. M., Collins, W. J., and Huntingford, C.: Indirect radiative forcing of climate change through ozone effects on the land-carbon sink, Nature, 448, 791-794, 2007.

Sparks, J. P., Walker, J., Turnipseed, A., and Guenther, A.: Dry nitrogen deposition estimates over a forest experiencing free air $\mathrm{CO}_{2}$ enrichment, Glob. Change Biol., 14, 768-781, 2008.

Stavrakou, T., Peeters, J., and Müller, J.-F.: Improved global modelling of $\mathrm{HO}_{\mathrm{x}}$ recycling in isoprene oxidation: evaluation against the GABRIEL and INTEX-A aircraft campaign measurements, Atmos. Chem. Phys., 10, 9863-9878, doi:10.5194/acp-10-98632010, 2010.

Steiner, A. L., Tonse, S., Cohen, R. C., Goldstein, A. H., and Harley, R. A.: Influence of future climate and emissions on regional air quality in California, J. Geophys. Res.-Atmos., 111, D18303, doi:10.1029/2007GL030802, 2006.

Steiner, A. L., Tonse, S., Cohen, R. C., Goldstein, A. H., and Harley, R. A.: Biogenic 2-methyl-3-buten-2-ol increases regional ozone and $\mathrm{HO}_{\mathrm{x}}$ sources, Geophys. Res. Lett., 34, L15806, doi:10.1029/2007GL030802, 2007.

Stroud, C., Makar, P., Karl, T., Guenther, A., Geron, C., Turnipseed, A. A., Nemitz, E., Baker, B., Potosnak, M., and Fuentes, J. D.: Role of canopy-scale photochemistry in modifying biogenicatmosphere exchange of reactive terpenoid species: Results from the CELTIC field study, J. Geophys. Res., 110, D17303, doi:10.1029/2005JD005775, 2005.

Tan, D., Faloona, I., Simpas, J. B., Brune, W., Shepson, P. B., Couch, T. L., Sumner, A. L., Carroll, M. A., Thornberry, T., Apel, E., Riemer, D., and Stockwell, W.: $\mathrm{HO}_{\mathrm{x}}$ budgets in a deciduous forest: Results from the PROPHET summer 1998 campaign, J. Geophys. Res.-Atmos., 106, 24407-24427, 2001.

Thomas, R. Q., Canham, C. D., Weathers, K. C., and Goodale, C. L.: Increased tree carbon storage in response to nitrogen deposition in the US, Nature Geoscience, 3, 13-17, doi:10.1038/ngeo721, 2010.

Thornton, J. A., Wooldridge, P. J., Cohen, R. C., Martinez, M., Harder, H., Brune, W. H., Williams, E. J., Roberts, J. M., Fehsenfeld, F. C., Hall, S. R., Shetter, R. E., Wert, B. P., and Fried, A.: Ozone production rates as a function of NOx abundances and $\mathrm{HO}_{\mathrm{x}}$ production rates in the Nashville urban plume, J. Geophys. Res., 107, 4146-4163, doi:10.1029/2001JD000932, 2002.
Turnipseed, A. A., Huey, L. G., Nemitz, E., Stickel, R., Higgs, J., Tanner, D. J., Slusher, D. L., Sparks, J. P., Flocke, F., and Guenther, A.: Eddy covariance fluxes of peroxyacetyl nitrates (PANs) and $\mathrm{NO}_{\mathrm{y}}$ to a coniferous forest, J. Geophys. Res., 111, D09304, doi:10.1029/2005JD006631, 2006.

Walton, S., Gallagher, M. W., and Duyzer, J. H.: Use of a detailed model to study the exchange of $\mathrm{NO}_{\mathrm{x}}$ and $\mathrm{O}-3$ above and below a deciduous canopy, Atmos. Environ., 31, 2915-2931, 1997.

Wesely, M. L.: Parameterization of surface resistances to gaseous dry deposition in regional-scale numerical models, Atmos. Environ., 23, 1293-1304, 1989.

Wesely, M. L. and Hicks, B. B.: A review of the current status of knowledge on dry deposition, Atmos. Environ., 34, 2261-2282, 2000.

Williams, E. J., Guenther, A., and Fehsenfeld, F. C.: An inventory of nitric oxide emissions from soils in the united states, J. Geophys. Res., 97, 7511-7519, 1992.

Wolfe, G. M. and Thornton, J. A.: The Chemistry of AtmosphereForest Exchange (CAFE) Model - Part 1: Model description and characterization, Atmos. Chem. Phys., 11, 77-101, doi:10.5194/acp-11-77-2011, 2011.

Wolfe, G. M., Thornton, J. A., Yatavelli, R. L. N., McKay, M., Goldstein, A. H., LaFranchi, B., Min, K.-E., and Cohen, R. C.: Eddy covariance fluxes of acyl peroxy nitrates (PAN, PPN and MPAN) above a Ponderosa pine forest, Atmos. Chem. Phys., 9, 615-634, doi:10.5194/acp-9-615-2009, 2009.

Wooldridge, P. J., Perring, A. E., Bertram, T. H., Flocke, F. M., Roberts, J. M., Singh, H. B., Huey, L. G., Thornton, J. A., Wolfe, G. M., Murphy, J. G., Fry, J. L., Rollins, A. W., LaFranchi, B. W., and Cohen, R. C.: Total Peroxy Nitrates (SPNs) in the atmosphere: the Thermal Dissociation-Laser Induced Fluorescence (TD-LIF) technique and comparisons to speciated PAN measurements, Atmos. Meas. Tech., 3, 593-607, doi:10.5194/amt-3-5932010, 2010.

Yienger, J. J. and Levy, H.: Empirical-Model Of Global SoilBiogenic Nox Emissions, J. Geophys. Res.-Atmos., 100, 1144711464, 1995

Zhang, L., Brook, J. R., and Vet, R.: A revised parameterization for gaseous dry deposition in air-quality models, Atmos. Chem. Phys., 3, 2067-2082, doi:10.5194/acp-3-2067-2003, 2003.

Zhang, L. M., Moran, M. D., Makar, P. A., Brook, J. R., and Gong, S. L.: Modelling gaseous dry deposition in AURAMS: a unified regional air-quality modelling system, Atmos. Environ., 36, 537560, 2002.

Zhou, X. L., Gao, H. L., He, Y., Huang, G., Bertman, S. B., Civerolo, K., and Schwab, J.: Nitric acid photolysis on surfaces in low-NOx environments: Significant atmospheric implications, Geophys. Res. Lett., 30, 2217, doi:10.1029/2003GL018620, 2003. 